\title{
The Modern Near-Surface Martian Climate: A Review of In-situ Meteorological Data from Viking to Curiosity
}

\author{
G.M. Martínez ${ }^{1}$ - C.N. Newman ${ }^{2}$ A. De Vicente-Retortillo ${ }^{3}$ - E. Fischer ${ }^{1}$. \\ N.O. Renno ${ }^{1}$ - M.I. Richardson ${ }^{2}$ - A.G. Fairén ${ }^{4,5}$ - M. Genzer ${ }^{6}$ - S.D. Guzewich ${ }^{7}$. \\ R.M. Haberle ${ }^{8}$ - A.-M. Harri ${ }^{6}$ - O. Kemppinen ${ }^{9}$ - M.T. Lemmon ${ }^{10}$ • M.D. Smith ${ }^{7}$. \\ M. de la Torre-Juárez ${ }^{11}$ - A.R. Vasavada ${ }^{11}$
}

Received: 18 November 2016 / Accepted: 26 March 2017 / Published online: 5 April 2017

(C) The Author(s) 2017. This article is published with open access at Springerlink.com

\begin{abstract}
We analyze the complete set of in-situ meteorological data obtained from the Viking landers in the 1970s to today's Curiosity rover to review our understanding of the modern near-surface climate of Mars, with focus on the dust, $\mathrm{CO}_{2}$ and $\mathrm{H}_{2} \mathrm{O}$ cycles and their impact on the radiative and thermodynamic conditions near the surface. In particular, we provide values of the highest confidence possible for atmospheric opacity, atmospheric pressure, near-surface air temperature, ground temperature, near-surface wind speed and direction, and near-surface air relative humidity and water vapor content. Then, we study the diurnal, seasonal and interannual variability of these quantities over a span of more than
\end{abstract}

The original version of this article was revised because due to an unfortunate turn of events a wrong value was published in Table 1 . The resolution of the PHX pressure sensor was published as " 0.1 mbar" whereas this value has now been corrected to " $0.1 \mathrm{~Pa}$ " which is the correct value and should be regarded as the final version by the reader.

\footnotetext{
$凶$ G.M. Martínez

gemartin@umich.edu

1 Department of Climate and Space Sciences and Engineering, University of Michigan, Ann Arbor, MI, USA

2 Aeolis Research, 600 N. Rosemead Blvd, Suite 205, Pasadena, CA 91107, USA

3 Departamento de Física de la Tierra, Astronomía y Astrofísica II, Universidad Complutense de Madrid, Madrid, Spain

4 Centro de Astrobiología (CSIC-INTA), 28850 Madrid, Spain

5 Department of Astronomy, Cornell University, Ithaca, NY 14853, USA

6 Earth Observation, Finnish Meteorological Institute, Erik Palménin aukio 1, Helsinki, Finland

7 NASA Goddard Space Flight Center, Greenbelt, MD, USA

8 Space Science Division, NASA Ames Research Center, Moffett Field, CA, USA

9 Department of Physics, Kansas State University, Manhattan, KS 66506-2601, USA

10 Department of Atmospheric Sciences, Texas A\&M University, College Station, TX 77843-3150, USA

11 Jet Propulsion Laboratory, California Institute of Technology, 4800 Oak Grove Drive, Pasadena, CA 91109, USA
} 
twenty Martian years. Finally, we propose measurements to improve our understanding of the Martian dust and $\mathrm{H}_{2} \mathrm{O}$ cycles, and discuss the potential for liquid water formation under Mars' present day conditions and its implications for future Mars missions. Understanding the modern Martian climate is important to determine if Mars could have the conditions to support life and to prepare for future human exploration.

Keywords Mars $\cdot$ Atmosphere $\cdot$ Climate $\cdot$ Meteorology

\section{Introduction}

The characterization of the modern near-surface climate of Mars is a high-priority goal of NASA's exploration program (MEPAG 2015). Understanding the climate of Mars is important to facilitate human exploration and to determine if Mars could have the conditions to support life.

Modern Mars exploration started in the early 1960s, with the first successful flyby by Mariner 4 and the return of the first close-up images of the Martian surface in 1965. The next milestones in the exploration of Mars were the Mariner 9 mission in 1971, the first spacecraft to orbit Mars, and the Viking missions in 1975, that included the first spacecraft to operate successfully on the surface of Mars. After a slowdown in the eighties, in 1996 the Mars Global Surveyor mission started a new era in the exploration of Mars that continues today. As of February 2017, six orbiters (Mars Reconnaissance Orbiter, Mars Express, Mars Odyssey, Mars Atmosphere and Volatile Evolution, Mars Orbiter Mission and ExoMars Trace Gas Orbiter) and two rovers (Mars Exploration Rover Opportunity (MER-B) and Mars Science Laboratory (MSL) Curiosity) are operating at Mars. Furthermore, the exploration of Mars continues with the InSight geophysical lander scheduled for launch in 2018, the ExoMars rover in 2020, and the Mars 2020 rover in the same year.

Analyses of ground-based and satellite observations from twenty-one missions over more than 50 years have led to a robust understanding of the modern Martian climate. We learned that the $\mathrm{CO}_{2}$, dust, and $\mathrm{H}_{2} \mathrm{O}$ cycles, coupled to radiative and dynamical processes, regulate the modern climate of Mars. On a global scale, the Martian atmospheric circulation is impacted strongly by the seasonal sublimation and deposition of $\mathrm{CO}_{2}$ at high latitudes, with about $30 \%$ of the atmosphere being cycled annually through the seasonal caps (Hess et al. 1980). The annual retreats and advances of the Martian seasonal caps are forced by strong asymmetries in solar insolation at the top of the atmosphere (TOA) caused by the Martian axial tilt $\left(25.2^{\circ}\right.$ vs. $23.4^{\circ}$ on Earth) and large orbit eccentricity $(\mathrm{e}=0.0934$; about 5.6 times larger than that of Earth), which cause the southern hemisphere to have warmer and shorter summers and colder and longer winters than the northern hemisphere. Due to its larger eccentricity, Mars takes 687 Earth days or 668.6 Martian days (also referred to as 'sols', and with a an approximate mean period of $24 \mathrm{~h}$ and $39^{\prime}$ ) to complete one orbit around the Sun. Martian seasons are defined by the solar longitude $\left(L_{\mathrm{s}}\right)$ along the ecliptic of Mars' sky. $L_{\mathrm{s}}$ ranges from $0^{\circ}$ to $360^{\circ}$ over one Mars year, with $L_{\mathrm{s}}=0^{\circ}, 90^{\circ}, 180^{\circ}$ and $270^{\circ}$ defining the Mars northern hemisphere vernal equinox, summer solstice, autumnal equinox and winter solstice, respectively. The Martian perihelion occurs at $L_{\mathrm{s}, \mathrm{p}}=251^{\circ}$, prior to the beginning of summer in the southern hemisphere $\left(L_{\mathrm{s}}=270^{\circ}\right)$, while the Martian aphelion occurs at $L_{\mathrm{s}, \mathrm{a}}=71^{\circ}$, prior to the beginning of winter in the southern hemisphere $\left(L_{\mathrm{s}}=90^{\circ}\right)$.

Along with the $\mathrm{CO}_{2}$ cycle, the dust cycle has a significant impact on the Martian atmospheric structure and circulation (Haberle et al. 1982; Read and Lewis 2004; Smith 2004). The Martian atmosphere transports large amounts of dust, which interacts with solar 


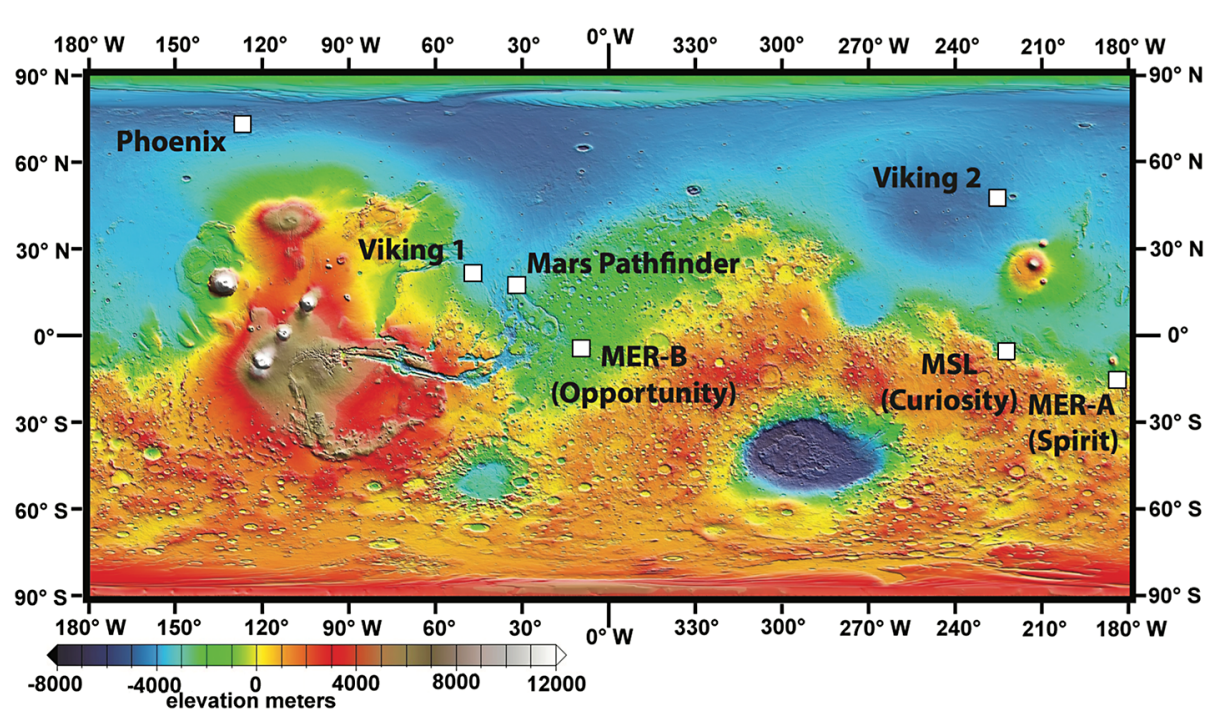

Fig. 1 Map with the large asymmetry in topography and the landing sites of spacecraft that landed successfully on Mars

and infrared radiation, regulating atmospheric and surface heating rates and thus influencing the Martian climate (Gierasch and Goody 1972; Kahn et al. 1992; Forget et al. 1999; Basu et al. 2004; Madeleine et al. 2011). The Martian regolith forms a loosely packed, porous medium, which is the source of the ubiquitous airborne dust and allows the exchange of volatiles with the atmosphere. The large spatial and temporal variability in atmospheric dust content creates complex feedbacks connecting dust lifting and transport with the evolving atmospheric circulations (Newman et al. 2002a, 2002b; Basu et al. 2004; Kahre et al. 2006; Madeleine et al. 2011). As an example of such feedback, Martian global dust storms occur every few years, enshrouding the entire planet with dust in just a few weeks. On a global scale, the most vigorous dust activity and the resulting largest dust opacity values occur during southern spring and summer (Martin 1986; Smith 2004, 2008; Montabone et al. 2015), when regional dust storms persist throughout the southern hemisphere and the northern baroclinic zone. Smaller regional dust events also persist throughout the northern spring and summer, but they are less efficient at increasing the overall atmospheric dust opacity than the southern spring and summer events (Cantor et al. 2001). The southern hemisphere surface is on average around $5 \mathrm{~km}$ higher than the northern hemisphere surface (e.g., Smith et al. 1999) (Fig. 1), and this asymmetry in topography alone would produce a more intense Hadley circulation in southern spring and summer (Joshi et al. 1995; Richardson and Wilson 2002). In combination with the asymmetry in solar insolation, which also favors this time of year, the result is a far stronger overturning circulation and stronger surface wind stresses (and hence dust lifting from the surface) during the so-called 'dust storm season,' which runs from $L_{\mathrm{s}} \sim 180-330^{\circ}$ (see also Sect. 3.1).

Mars also has a strong seasonal $\mathrm{H}_{2} \mathrm{O}$ cycle by which water is exchanged between the surface and the atmosphere through various processes, and then redistributed in the atmosphere by atmospheric circulations (Jakosky and Farmer 1982; Jakosky 1985; Jakosky and Haberle 1992; Houben et al. 1997; Richardson and Wilson 2002; Mischna et al. 2003). Seasonal water reservoirs include water ice on or within the seasonal or residual polar caps, surface or subsurface ice in high-latitude regions, physically adsorbed and chemically- 
bound water within the near-surface regolith, and possibly surface and subsurface liquid water in the form of liquid saline solutions (brine) (Jakosky 1985). Satellite and telescopic observations of variations in the integrated $\mathrm{H}_{2} \mathrm{O}$ column abundance (Conrath et al. 1973; Jakosky and Farmer 1982; Sprague et al. 1996; Smith 2004; Fedorova et al. 2006; Fouchet et al. 2007; Melchiorri et al. 2006), in combination with numerical modeling, have been used to determine the relative importance of the various processes controlling the seasonal $\mathrm{H}_{2} \mathrm{O}$ cycle (Flasar and Goody 1976; Jakosky and Farmer 1982; Haberle and Jakosky 1990; Richardson and Wilson 2002; Böttger et al. 2005). The seasonal $\mathrm{H}_{2} \mathrm{O}$ cycle is important for the Martian climate because it leads to the formation and affects the stability of water ice deposits on the surface and of water ice clouds in the atmosphere (Jakosky and Haberle 1992; Richardson and Wilson 2002; Smith et al. 1997; Haberle et al. 1999; Montmessin et al. 2004; Madeleine et al. 2012).

The goal of this article is to analyze the complete set of in-situ meteorological measurements from the 1970s Viking landers to the current Curiosity rover in order to review our understanding of the modern climate of Mars, with focus on the dust, $\mathrm{CO}_{2}$ and $\mathrm{H}_{2} \mathrm{O}$ cycles and their impact on the near-surface radiative and thermodynamic conditions. In particular, we examine ground-based measurements made by the Viking Lander 1 (VL1), Viking Lander 2 (VL2), Mars Pathfinder (MPF) lander and Sojourner rover, Mars Exploration Rover A (MER-A, Spirit) and B (MER-B, Opportunity), Phoenix lander (PHX) and Mars Science Laboratory (MSL, Curiosity) rover (Fig. 1). We provide values of atmospheric opacity, atmospheric pressure, near-surface air temperature, ground temperature, near-surface wind speed and direction, and near-surface air relative humidity and water vapor content with the highest confidence possible and study the diurnal, seasonal and interannual variability of these quantities at the various landing sites over a span of more than twenty Martian years. Although satellite observations and modeling have contributed significantly to our understanding of the Martian climate, in this article we focus only on ground-based measurements.

Section 2 describes the characteristics and performance of the meteorological instruments onboard each spacecraft that landed successfully on Mars. Section 3 shows the results of the data analysis, including diurnal, seasonal and interannual variations of atmospheric opacity (Sect. 3.1), atmospheric pressure (Sect. 3.2), near-surface air temperature (Sect. 3.3), ground temperature (Sect. 3.4), near-surface wind speed and direction (Sect. 3.5), and nearsurface relative humidity and water vapor content (Sect. 3.6). Section 4 describes the meteorological stations being developed for future missions to Mars (Sect. 4.1), proposes further measurements to improve our understanding of the Martian dust and $\mathrm{H}_{2} \mathrm{O}$ cycles (Sect. 4.2), and discuss the potential for liquid water formation under Mars' present day conditions and its implications for future Mars missions (Sect. 4.3). Finally, Sect. 5 summarizes the main results.

\section{Meteorological Stations on Mars}

Over the last 40 years, in-situ measurements made by meteorological instruments onboard various landers and rovers have been used to study the climate of Mars. Here, we review these instruments, including their goals, locations, sensors, performances, operations and main findings. Table 1 summarizes these instruments.

\subsection{Viking Lander Missions}

After several failures, the first successful meteorological observations from the Martian surface were made in 1976 by the two Viking landers (Chamberlain et al. 1976; Hess et al. 1977; Tillman et al. 1994). The main goals of these meteorological observations were to study 


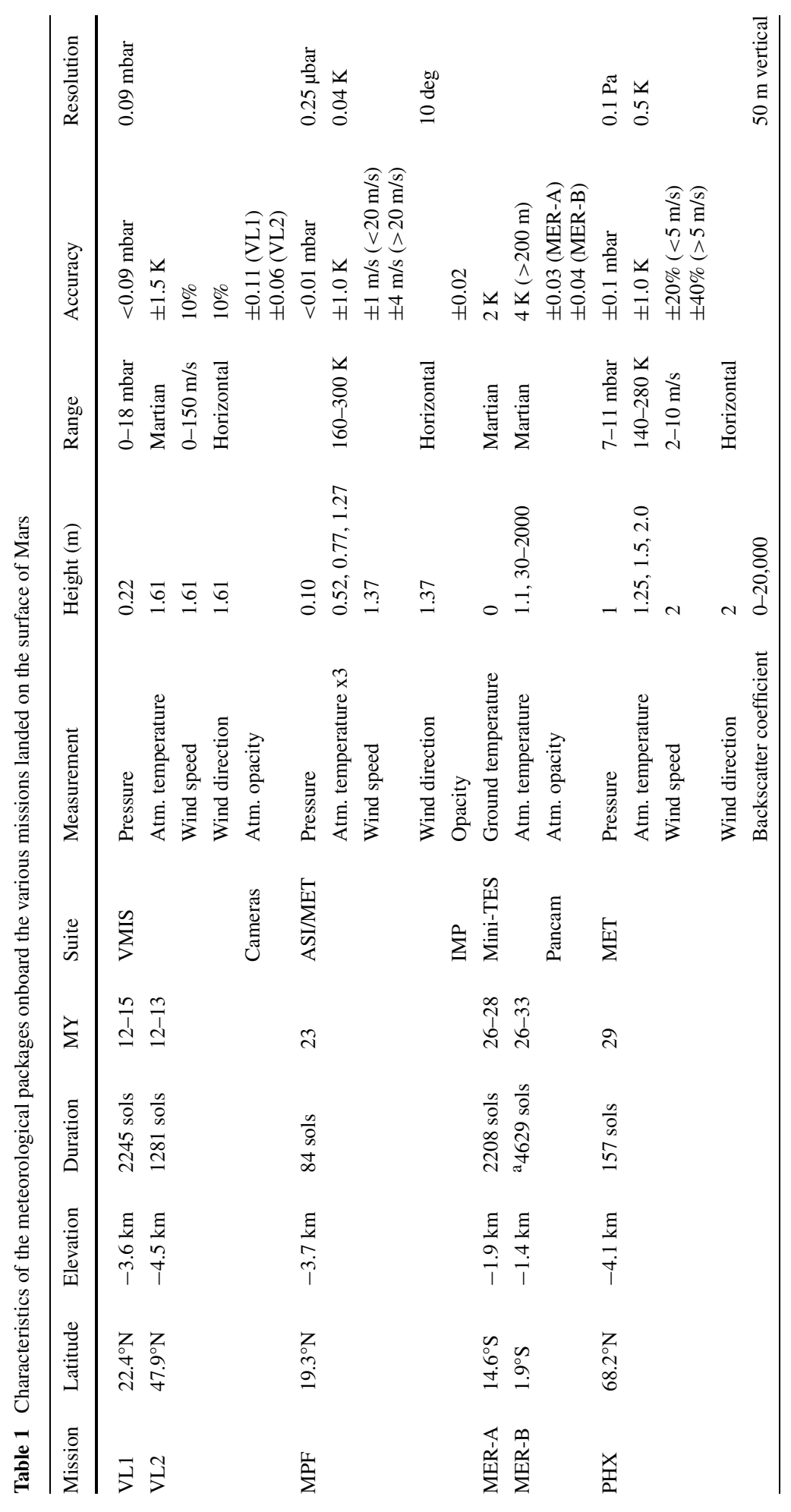




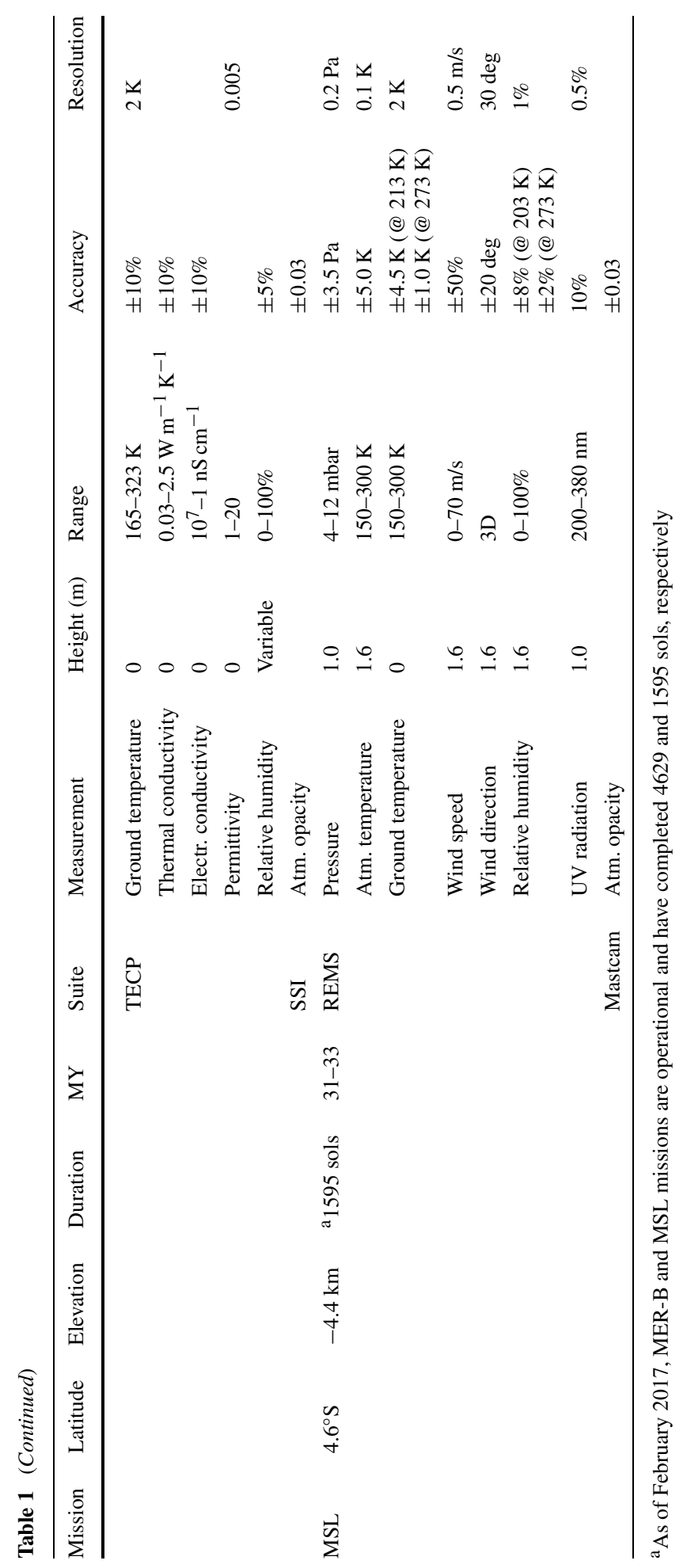


meso-scale and planetary-scale systems and processes, to investigate boundary layer phenomena and to obtain a better understanding of the Earth's atmosphere through comparison with that of Mars. The VL1 landed at $22.4^{\circ} \mathrm{N}$ and collected data for 2245 sols, while the VL2 landed at $47.9^{\circ} \mathrm{N}$ and operated for 1281 sols. Both landers far surpassed their design lifetime.

The Viking Meteorology Instrument System (VMIS) onboard VL1 and VL2 consisted of sensors to measure atmospheric temperature, wind velocity and direction at $1.61 \mathrm{~m}$ above the ground, and pressure at $0.22 \mathrm{~m}$ above ground. The Viking landers measured temperature and wind in modules of $9 \mathrm{~min}$ at 0.25 or $0.125 \mathrm{~Hz}$ sampling rate, 20 min at $0.5 \mathrm{~Hz}$ sampling rate, or $39 \mathrm{~min}$ at $0.25 \mathrm{~Hz}$ sampling rate, spaced $1.5 \mathrm{~h}$ apart throughout the sol. In addition, operational modes consisting of extended periods of sampling at $1 \mathrm{~Hz}$ were used. Initially, four pressure measurements at $1 \mathrm{~Hz}$ were made at the start of every module, but this was later reduced to one sample every $17 \mathrm{~min}$ (Hess et al. 1977). The data acquisition frequency was reduced towards the end of the landers' lives. Furthermore, dust opacities at the two landing sites were determined from Sun images obtained by the cameras at a wavelength of $670 \mathrm{~nm}$ over a span of more than one Martian year (Colburn et al. 1989). These dust opacity measurements cover 328 out of the first 920 sols of VL1 and 250 out of 872 sols of VL2. The range, accuracy and resolution of the various VMIS sensors are summarized in Table 1.

Problems with VMIS onboard VL2 started on sol 25 when its temperature sensor had its first anomaly. From this sol onward, a VL2 engineering sensor was used for making temperature measurements, with a worst-case reduced accuracy of $\pm 4{ }^{\circ} \mathrm{C}$ (Hess et al. 1977; Sutton et al. 1978). Problems with VMIS onboard VL1 started on sol 45 when the heater of the wind direction sensor failed. This could be partially corrected until sol 376, when one of the two hot film wind sensors failed (Murphy et al. 1990).

\subsection{Mars Pathfinder Mission}

After a hiatus in in-situ surface measurements on Mars throughout most of the 1980s and the first half of the 1990s, the MPF lander re-started in-situ meteorological measurements in July of 1997 (Seiff et al. 1997; Schofield et al. 1997). As part of NASA's "faster, better, cheaper" strategy, MPF was a low-cost mission intended to operate for 30 sols. The goal of the MPF meteorological measurements was to study the variability of the Martian atmosphere at Ares Valley during the midsummer season on diurnal and seasonal time scales and compare the data with that from the VL1 obtained at the same time of the year. MPF landed at $19.3^{\circ} \mathrm{N}$ and operated for 84 sols.

The Atmosphere Structure Instrument/Meteorology package (ASI/MET) experiment had similar meteorological sensors to those of the Viking landers: a pressure sensor in the lander body at $0.1 \mathrm{~m}$ height above the surface, three atmospheric temperature sensors at $0.25,0.5$ and $1 \mathrm{~m}$ above the lander deck, which is at $0.27 \mathrm{~m}$ above the ground, a wind sensor at $1.1 \mathrm{~m}$ above the lander deck and three wind socks placed between the temperature sensors (see Table 1 for details on the instruments). ASI/MET measurements were made at a rate of 51 sessions per day, each 3 min long at a sampling rate of $0.25 \mathrm{~Hz}$. Additionally, MPF conducted various $15 \mathrm{~min}$ and $1 \mathrm{~h}$ sessions at $1 \mathrm{~Hz}$, and one complete $24 \mathrm{~h}$ session at $0.25 \mathrm{~Hz}$. Dust opacities were obtained from direct images of the Sun acquired by the Imager for Mars Pathfinder (IMP). Smith and Lemmon (1999) provided several atmospheric opacity values per sol at four wavelengths $(450,670,883$ and $989 \mathrm{~nm})$ on 70 out of the 83 sols of the mission.

The ASI/MET hot wire wind sensor experienced problems because it relied on the difference in response during adjacent periods with and without heating of the sensor. Unfortunately, the imposed temperature difference was comparable to (only a few times larger than) 
the natural temperature fluctuations of the daytime near surface air. In addition, nighttime temperatures were lower than those for which the sensor had been calibrated. Thus, the MPF wind data is not available in the NASA PDS. However, wind direction could be retrieved with an uncertainty of $\sim 15^{\circ}$ (Schofield et al. 1997). In addition, eight sequences of measurements were made using the windsocks and several of these measurements were used to deduce the wind profile (Sullivan et al. 2000). The MPF pressure sensor also had calibration problems (Haberle et al. 1999). During pre-flight testing, the pressure sensor was tested at temperatures that were significantly lower than its design limits $(220 \mathrm{~K})$, and much lower than it experienced within the spacecraft on the Martian surface (265-300 K). It appears that this extreme stressing changed the sensor offset and caused an increase in the variation of the offset with temperature. It was not possible to verify the sensor gain in flight, but laboratory tests with the spare flight sensor suggested that the sensor stressing would not produce significant changes in gain.

\subsection{Mars Exploration Rover missions}

Similar to the Viking mission, the MER mission delivered two systems to the surface of Mars in January of 2004. The meteorology science goal of the MER mission was to provide high vertical resolution temperature profiles in the boundary layer, to measure dust and ice aerosol optical depth, and to determine aerosol properties from imaging (Squyres et al. 2003). MER-A (Spirit) landed at $14.6^{\circ} \mathrm{S}$ and operated for 2208 sols. MER-B (Opportunity) landed at $1.9^{\circ} \mathrm{S}$ and has been operating for more than 4638 sols as on Feb. 9, 2017.

The MER rovers do not have a dedicated set of environmental instruments (i.e., a meteorology station) like those of the previous missions. Instead, thermal infrared spectra of the Martian atmosphere taken by the Miniature Thermal Emission Spectrometer (Mini-TES) were used to determine surface temperature, near-surface air temperature at about $1.1 \mathrm{~m}$, atmospheric temperatures at altitudes ranging from about 30 to $2000 \mathrm{~m}$, and column-integrated values of dust optical depth and water vapor abundance (Smith et al. 2004, 2006; Spanovich et al. 2006). Mini-TES infrared spectra in 167 channels from 340 to $1997 \mathrm{~cm}^{-1}$ with a spectral resolution of $10 \mathrm{~cm}^{-1}$ were acquired at rates of $0.5 \mathrm{~Hz}$. The Mini-TES spatial resolution is $20 \mathrm{mrad}$. Mini-TES typically conducted between one and four atmospheric observation sequences per sol. Nighttime observations were rare (Smith et al. 2006), with the vast majority of the measurements being made between 09:00 and 18:00 Local Mean Solar Time (LMST). Observations with Mini-TES pointing upward were made either at three fixed elevations scan in sets of 100 spectra each, or as a "stare" at a single elevation angle (typically $30^{\circ}$ ) in sets of 100-1275 spectra. Observations with Mini-TES pointing downward in sets of 10 spectra were used to measure the surface temperature and the near-surface air temperature. Even though Opportunity is still active, Mini-TES stopped operating when a globalscale dust storm obscured its mirrors in Mars Year (MY) 28. Ground and near-surface air temperature retrievals were made for the MER-A first 1124 sols and the MER-B first 1110 sols.

Atmospheric opacities at the MER landing sites are also obtained from direct images of the Sun at the wavelengths of 440 and $880 \mathrm{~nm}$ with the Pancam cameras (Lemmon et al. 2015). MER measurements have produced the most complete atmospheric opacity dataset available from the surface of Mars, with the MER-A dataset spanning more than 2200 sols, and the MER-B dataset so far spanning more than 4600 sols as of February 2017. The datasets presented here include results of measurements during 2030 sols for MER-A and 4010 sols for MER-B. Here, we use atmospheric opacity values obtained by Pancam instead of from Mini-TES measurements because the Pancam instrument provides a more complete coverage and are available in the NASA PDS. 


\subsection{Phoenix Mission}

The Phoenix mission landed at $68.2^{\circ} \mathrm{N}$ in May of 2008 to study the history of water in the Martian Arctic and to search for environments suitable for microbial life. It operated for 151 sols, exceeding the mission design life of 90 sols.

PHX carried a meteorological station (MET) containing sensors to measure air temperature at heights of $1.25,1.5$ and $2 \mathrm{~m}$ above the surface, sensors to measure air pressure, and a "telltale" to measure wind at $2 \mathrm{~m}$ above the surface (Taylor et al. 2008; Holstein-Rathlou et al. 2010). The characteristics of the MET sensors are listed in Table 1. The MET instrument measured temperature and pressure at a rate of $0.5 \mathrm{~Hz}$ throughout the duration of the mission. The data could be processed on board to produce mean, standard deviation, minimum and maximum values within a $512 \mathrm{~s}$ window to reduce communication requirements. As part of the MET instrument, Phoenix also included a light detection and ranging (LIDAR) system to probe the vertical structure of the atmospheric boundary layer using pulsed laser light with wavelength of $532 \mathrm{~nm}$ backscattered from dust and ice particles from $\sim 200 \mathrm{~m}$ to $\sim 20 \mathrm{~km}$ above the ground (Whiteway et al. 2008). The optical extinction coefficient derived from the LIDAR signal can then be related to the ice-water content (IWC) profile to resolve the internal structure of water-ice clouds (Whiteway et al. 2009; Daerden et al. 2010; Dickinson et al. 2010; Moores et al. 2011). In addition, Phoenix's Thermal and Electrical Conductivity Probe (TECP) was used to measure subsurface and near-surface temperature, conductivity, permittivity and humidity (Hecht et al. 2008; Zent et al. 2009). The TECP consisted of a single electronics box, fitted with four needles, which could be inserted into the Martian soil, and was mounted on the Phoenix Robotic Arm. Atmospheric opacity measurements were obtained from direct images of the Sun by the Phoenix's Surface Stereo Imager (SSI) at the wavelengths of 451, 671, 887 and $991 \mathrm{~nm}$. Opacities are available for 117 out of the 151 sols of the mission (Tamppari et al. 2010).

Wind data could only be obtained when the SSI was used to observe the telltale, a simple Kapton cylinder hanging from a Kevlar string in front of a mirror (Gunnlaugsson et al. 2008). A source of uncertainty in MET temperature measurements is lander-generated heat; this uncertainty is expected to be most severe on the lowest thermocouple for wind from $340^{\circ}$ to $90^{\circ}$ and from $240^{\circ}$ through $310^{\circ}$, the directions of the solar panel. Another source of uncertainty in the temperature measurements is direct sunlight on the thermocouples, which can cause errors of up to $1 \mathrm{~K}$ (Davy et al. 2010).

Only the raw output of the TECP Relative Humidity (RH) sensor (unprocessed RH values) is available at the NASA PDS because of uncertainties in pre-flight instrument calibration. Values of temperature and RH covered in the pre-flight calibration (Zent et al. 2009) overlap only partially with the environmental conditions found at the Phoenix landing site (Tamppari et al. 2010; Davy et al. 2010). The calibration function was revised in 2016 to correct for inaccuracies at the lowest temperatures observed at the Phoenix landing site (Zent et al. 2016), but the new processed RH values are not available in the PDS yet.

\subsection{Mars Science Laboratory Mission}

The MSL Curiosity rover landed in Gale crater $\left(4.6^{\circ} \mathrm{S}\right)$ in August of 2012 and as of February 2017, it has been operating for almost 1600 sols. The main meteorological goals of the MSL mission are to study the climate, water and $\mathrm{CO}_{2}$ cycles, and atmospheric processes ranging from local to synoptic scales.

Curiosity's Rover Environmental Monitoring Station (REMS) consists of wind velocity, air temperature, ground temperature, and air humidity sensors at $1.6 \mathrm{~m}$ height on the rover 
mast and pressure and UV sensors at $1 \mathrm{~m}$ on the rover deck (Gómez-Elvira et al. 2012, 2014). The REMS sampling strategy consists of 5 min-long hourly samples at $1 \mathrm{~Hz}$ throughout the mission, with interspersed full hour sample periods at $1 \mathrm{~Hz}$ to cover every time of the sol over a period of a few sols. The cadence of full hour measurements is restricted by memory size and downlink data times and volume. The range, accuracy and resolution of the REMS sensors are listed in Table 1. Atmospheric dust opacities are obtained from direct images of the Sun at the wavelengths of 440 and $880 \mathrm{~nm}$ by the Mastcam instrument (Smith et al. 2016). In this manuscript, we analyze REMS and Mastcam measurements corresponding to the first 1526 sols of the MSL mission.

Because the REMS temperature sensor is located only about $0.6 \mathrm{~m}$ above the rover deck, the heating of the rover by solar radiation and by the Radioisotope Thermoelectric Generator (RTG) may affect the air temperature measurements. In addition, the rover affects ground temperature measurements because the field of view of the Ground Temperature Sensor (GTS) is within the area of the ground heated by thermal radiation from the RTG. Indeed, the RTG can contribute up to $4 \mathrm{~K}$ to the measured ground temperature (Hamilton et al. 2014). The RH sensor is affected by heating produced by the sensor itself, which increases its temperature by up to $\sim 1.5 \mathrm{~K}$ minutes after it is turned on. Thus, the local RH measured by the sensor is closest to the actual RH of the atmosphere only during the first few seconds of operation, and values of the water vapor volume mixing ratio (VMR) derived from these measurements represent the VMR of the atmosphere. In long measurement sessions, the temperature of the RH sensor stabilizes after $\sim 30$ min and then starts to follow changes in the atmospheric temperature, making derived VMR values again representative of atmospheric values. The data obtained during the transient heating period ( $\sim 30 \mathrm{~min}$ ) may be retrieved by compensating for the heating effect; this requires additional analysis, which is planned for the future. Furthermore, the RH sensor response time is a logarithmic function of temperature, ranging from $0.1 \mathrm{~s}$ at $293 \mathrm{~K}$ to $700 \mathrm{~s}$ at $203 \mathrm{~K}$, but the sensor adjusts to a changing $\mathrm{RH}$ while turned off and therefore provides correct values immediately upon being turned on (Gómez-Elvira et al. 2012). Recent laboratory measurements with a spare flight unit of the $\mathrm{RH}$ sensor in a low pressure $\mathrm{CO}_{2}$ environment indicate that low raw values measured on Mars are actually the result of $\mathrm{CO}_{2}$ effects on the Humicaps, supporting the use of the compensation method described by Harri et al. (2014). According to the preliminary results of the laboratory measurements, the dynamic range of the sensor does not change in a low pressure $\mathrm{CO}_{2}$ atmosphere (Harri et al. 2016).

MSL has two wind sensor booms mounted on the remote sensing mast (RSM), but after landing the side-rear-facing sensor was damaged and only two sensor boards on the front-facing boom have been working properly. Since the rover body (primarily the RSM) strongly disturbs wind reaching the remaining boom from the rear of the rover, the wind sensor can only be used to retrieve wind speeds and accurate wind directions when wind comes from the hemisphere in front of the rover. 'Rear' wind directions are retrieved with a much lower accuracy and wind speeds measurements are not reliable. Wind measurements are not available during the coldest periods of each sol (lasting between four and ten hours in local summer and winter, respectively) because of high electronic noise due to the performance of the Application-Specific Integrated Circuit (ASIC)-based Sensor Front-End, which transmits the wind data to the rover (Newman et al. 2017). However, 'wind characterization' campaigns - in which the rover is pointed in multiple directions over several sols-have been performed at various times and locations to provide the most complete wind information possible (Newman et al. 2017). Here we show results from one campaign only, although the full REMS wind speed and direction dataset is available in the PDS. 


\section{Results}

In this section we analyze meteorological measurements from the Viking landers to the Curiosity rover to provide values of atmospheric opacity (Sect. 3.1), atmospheric pressure (Sect. 3.2), near-surface air temperature (Sect. 3.3), ground temperature (Sect. 3.4), nearsurface wind speed and direction (Sect. 3.5), and near-surface relative humidity and water content (Sect. 3.6) over a span of more than twenty Martian years.

\subsection{Atmospheric Opacity and Surface Radiative Environment}

Here we analyze atmospheric opacity measurements taken at $670 \mathrm{~nm}$ by the VL cameras, $883 \mathrm{~nm}$ by the MPF/IMP, $880 \mathrm{~nm}$ by the MER/Pancam cameras, $887 \mathrm{~nm}$ by the PHX/SSI and $880 \mathrm{~nm}$ by the MSL/Mastcam. In combination with values of the atmospheric opacity, we provide estimated values of the surface solar insolation (defined as the solar irradiance integrated over one sol) at each landing site to show the impact of atmospheric opacity on the surface radiative environment.

Figure 2 (left column) shows the atmospheric opacity values at the VL1, VL2, MPF, MER-A, MER-B, PHX and MSL landing sites as a function of solar longitude. Among these missions, only the MERs and MSL can be used to study the interannual variability of the atmospheric opacity (Figs. 2c, 2e and 2g), with VL1 and VL2 measurements barely overlapping in $L_{\mathrm{s}}$ during MY 12 and MY 13 (Fig. 2a). During the aphelion season $\left(L_{\mathrm{s}}=0^{\circ}-\right.$ $180^{\circ}$ ), the opacity values are low (generally below 1 , which indicates that the direct radiation at the surface has been reduced to $\exp \left(-1 / \mu_{0}\right)$ times its value at the top of the atmosphere, where $\mu_{0}$ is the cosine of the solar zenith angle assuming a plane-parallel atmosphere), and the interannual variability is small (mean standard deviation around 0.05 and 0.03 at MER-A and MER-B locations). On the contrary, the opacity values and their interannual variability are larger during the perihelion season $\left(L_{\mathrm{s}}=180^{\circ}-360^{\circ}\right)$ at each landing site (Fig. 2, left column). Differences in solar insolation between the perihelion and aphelion seasons produce on average higher temperatures during the perihelion season, enhancing the injection of dust into the atmosphere via wind stress and dust devils (Haberle et al. 1982; Newman et al. 2002a, 2002b; Kahre et al. 2006; Greeley et al. 2010). Satellite measurements of atmospheric opacity show similar aphelion-versus-perihelion behavior on a planet-wide scale (Smith 2004; Cantor et al. 2001; Montabone et al. 2015).

Global dust storms, which occur every few years, are of particular interest because of their large impact on the atmospheric circulation and surface radiation budget. So far, these global dust storms have been observed from the surface only by the VL1 and VL2 in MY 12, and by the MER-A and MER-B in MY 28 (Figs. 2a, 2c and 2d). In both years, the peak atmospheric opacity was extraordinarily high $(\tau>3)$ and occurred shortly after the perihelion, at $L_{\mathrm{s}} \sim 300^{\circ}$ in MY 12 and at $L_{\mathrm{s}} \sim 280^{\circ}$ in MY 28 . Interestingly, in years when global dust storms did not occur, a local minimum in the atmospheric opacity occurred around this time (Figs. 2c, 2e and 2g). A global dust storm has not occurred since the Curiosity rover started operations at Gale crater (Fig. 2g). The MPF and PHX missions did not observe any major dust storms because they were short and ended prior to the beginning of the dusty season ( $L_{\mathrm{S}}=188^{\circ}$ and $148^{\circ}$, respectively).

Despite the large interannual variability observed at each landing site during the perihelion season, there are common aspects in the evolution of the atmospheric opacity during this season. At each landing site, two periods of enhanced dust activity were observed each year, the first period between $L_{\mathrm{s}}=210^{\circ}$ and $240^{\circ}$, and the second between $L_{\mathrm{s}}=320^{\circ}$ and $340^{\circ}$ (Fig. 2, left column). A third period of enhanced dust activity is apparent at the MERA landing site between $L_{\mathrm{s}}=150-170^{\circ}$ (Fig. 2c). The values of atmospheric opacity at the 


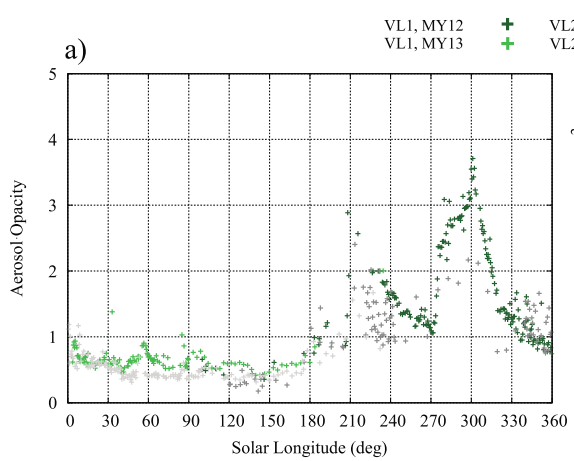

$\begin{array}{lll}\text { VL2, MY12 } & + \text { VL1, TOA } \\ \text { VL2, MY13 } & + \text { VL2, TOA }\end{array}$

b)
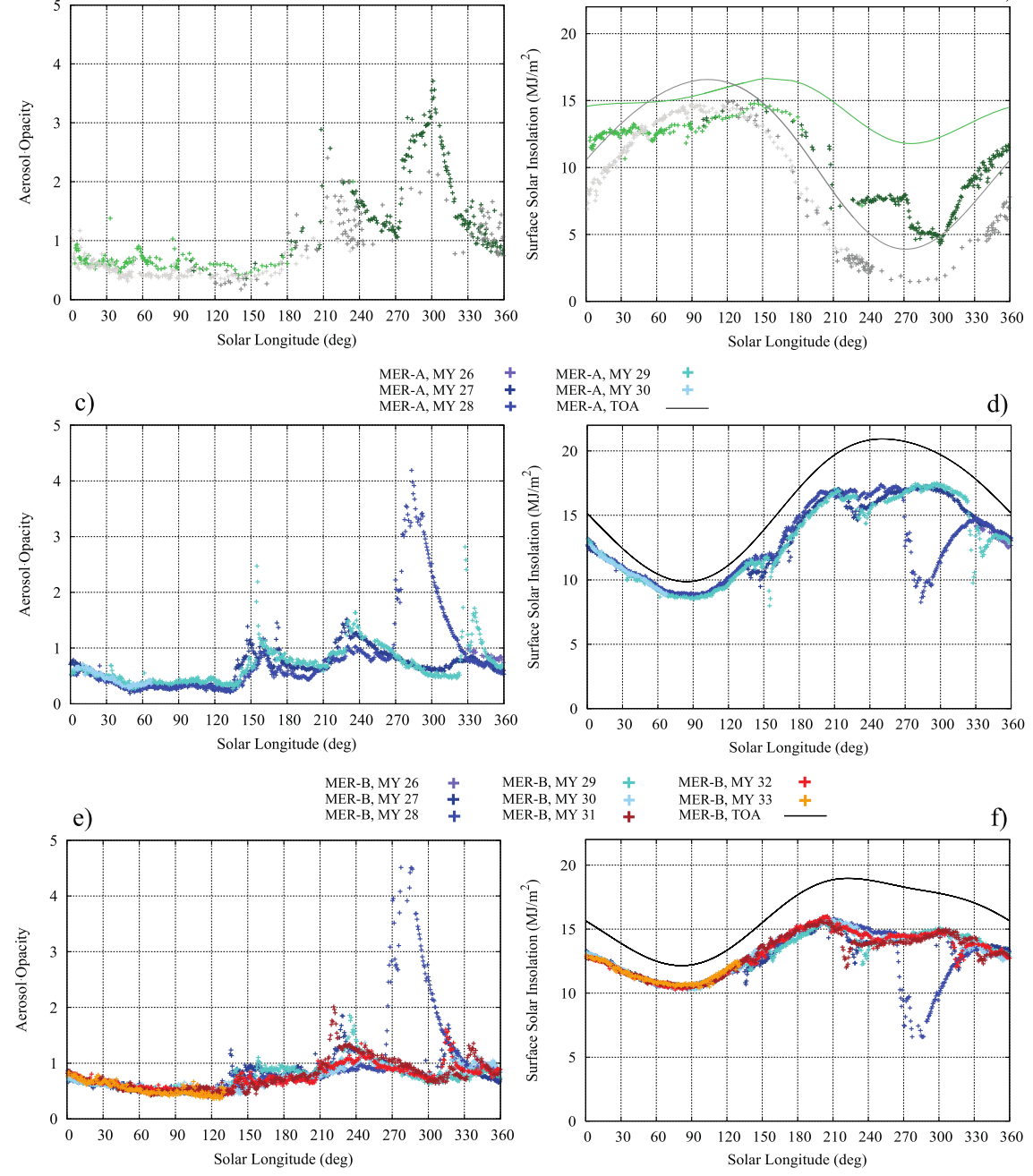

g)

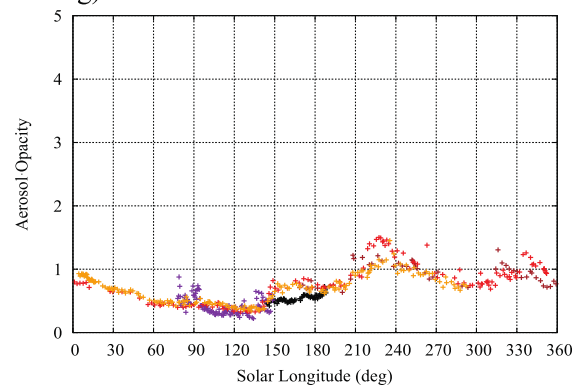

$\begin{array}{llllll}\text { MPF, MY23 } & + & \text { MSL, MY33 } & + & \text { PHX, TOA } & - \\ \text { PHX, MY29 } & + & \text { MSL, MY32 } & + & \text { MSL, TOA } & -\end{array}$

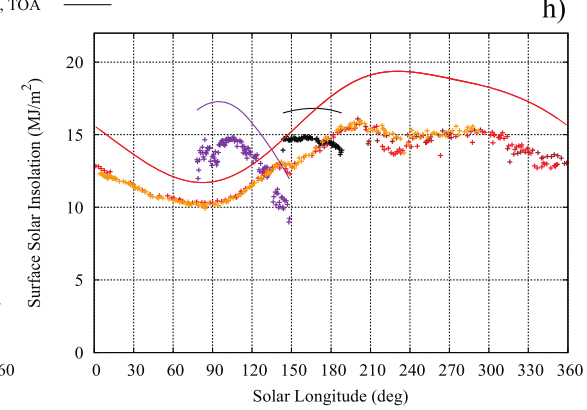

Fig. 2 Interannual and seasonal evolution of the aerosol opacity and solar insolation at the VLs (a-b), MER-A (c-d), MER-B (e-f), MPF, PHX and MSL (g-h), landing sites 
MER-B and MSL sites during this period were relatively high but did not present clear peaks (Figs. 2e and 2g). Although dust opacity measurements were only taken during the first 920 sols of the VL1 mission (corresponding to MY 12 and 13), analysis of air temperature data suggests that major dust storms also occurred between $270^{\circ}$ and $300^{\circ}$ in MY 14 , and at around $210^{\circ}$ in MY 15 (Savijärvi 2014).

Figure 2 (right column) shows the seasonal and interannual variability of the solar insolation at the TOA (solid lines) and at the surface (crosses) at each landing site. A comprehensive spectral radiative transfer model with the latest wavelength-dependent radiative properties of dust, water ice clouds and atmospheric gases is used to estimate the solar insolation at the surface, with values of atmospheric opacity measured at each landing site as inputs (Vicente-Retortillo et al. 2015). Although there are situations in which water ice clouds can significantly contribute to the atmospheric opacity, such as during the aphelion cloud belt or at the edges of the polar caps (Toigo and Richardson 2000; Smith 2004; Madeleine et al. 2012; Lemmon et al. 2015), their effect on the solar insolation at the surface is generally minor compared to that of the dust. To quantify this effect, we have used the radiative transfer model described in Vicente-Retortillo et al. (2015) to simulate the daily solar insolation at $L_{\mathrm{s}}=90^{\circ}$ (when opacity due to water ice clouds shows relatively high values), assuming that half of the opacity is caused by water ice clouds. The difference in the solar insolation at the various landing sites ranges from $3 \%$ to $5 \%$ with respect to values obtained when only dust is assumed to contribute to the atmospheric opacity.

Surface solar insolation departs from that at the TOA because the solar radiation is absorbed and scattered by atmospheric constituents such as dust particles. This is particularly noticeable during the dusty perihelion season, when abrupt changes in atmospheric dust content (Fig. 2, left column) cause strong intraseasonal and interannual variations in surface solar insolation (Fig. 2, right column). In contrast, during the aphelion season when dust activity declines, intraseasonal and interannual variations in solar insolation at each landing site are small, and the variation in surface solar insolation follows that at the TOA smoothly. However, water ice clouds can also partially contribute to variations in solar insolation during this season, which we are not considering here.

At the VL sites in the northern hemisphere, the decreasing trend of solar insolation at the TOA during the perihelion season (northern fall and winter; see solid lines in Fig. 2b) is further reduced at the surface by enhanced dust activity (Fig. 2a), while the increasing trend at the TOA during the aphelion season (northern spring and summer) coincides with the lowest annual values in atmospheric opacity, which further enhances the insolation at the surface. Consequently, the highest annual values of surface solar insolation at the VL1 and VL2 sites occur during the aphelion season at around $L_{\mathrm{s}} \sim 150^{\circ}$ and $120^{\circ}$, respectively. This is around the time that the insolation at the TOA is the highest and atmospheric opacity values are the lowest. In contrast, at the MER and MSL sites in the southern hemisphere, the increasing trend in solar insolation at the TOA during the perihelion season (southern spring and summer; see solid lines in Figs. $2 \mathrm{~d}, 2 \mathrm{f}$ and $2 \mathrm{~h}$ ) is counteracted at the surface by the increase in dust opacity (Figs. 2c, 2e and 2g). Therefore, the highest annual values of solar insolation at the MER and MSL sites occur each year at $L_{\mathrm{s}} \sim 200^{\circ}$ and $L_{\mathrm{s}} \sim 300^{\circ}$ (with the exception of MY 28 at both MER landing sites), coinciding with local minima in atmospheric opacity and relatively high values (but not annual maximum) of solar insolation at the TOA.

\subsection{Atmospheric Pressure}

Surface pressure variations depend on many processes. On seasonal time-scales, variations in the bulk atmospheric mass due to the condensation and sublimation of the sea- 
Fig. 3 Interannual and seasonal evolution of the daily mean atmospheric pressure (top) and the diurnal amplitude (difference between the daily maximum and minimum atmospheric pressure; bottom) at the VL1 (green colors), VL2 (gray colors), MPF (black), PHX (purple) and MSL (brown-red-orange) landing sites
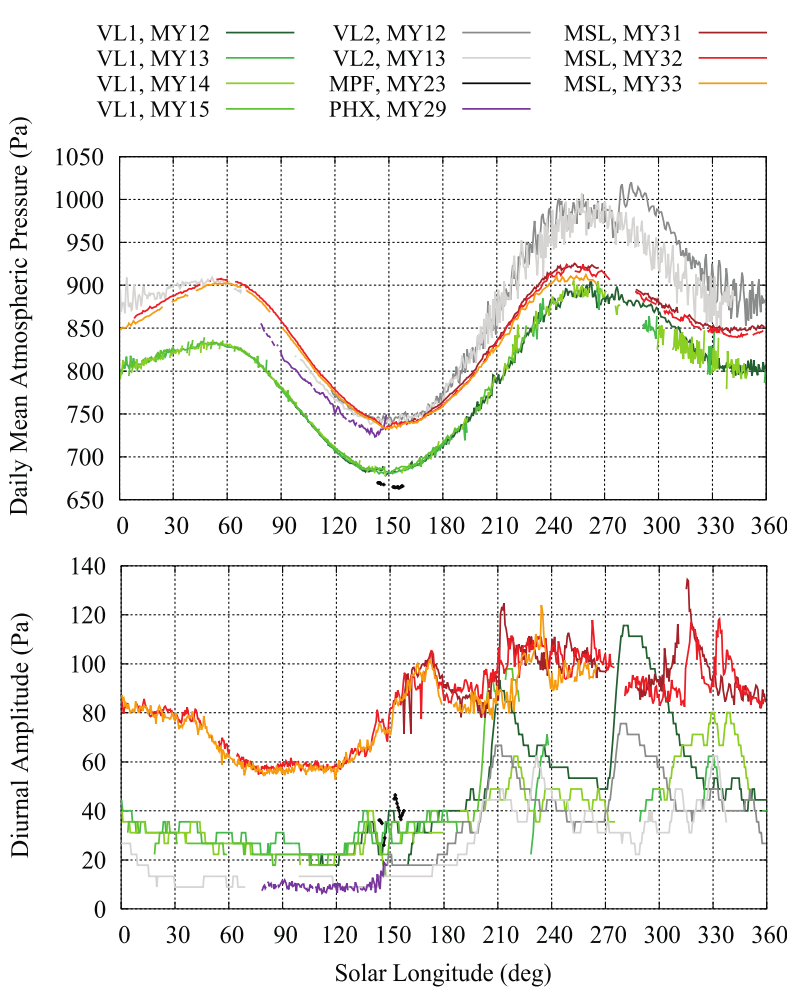

sonal polar caps cause large pressure variations across the planet (Hess et al. 1980; Tillman et al. 1993). On daily to monthly time scales, various components of the global circulation such as baroclinic eddies (Barnes 1980, 1981), tropical overturning circulations (Magalhães 1987; Haberle et al. 1993a; Forget et al. 1999; Read and Lewis 2004; Moudden and McConnell 2005), and stationary waves (Hollingsworth and Barnes 1996; Banfield et al. 2003; Hinson et al. 2003) are associated with changes in surface pressure. On diurnal time scales, the global scale thermal tides (Zurek 1976; Zurek and Leovy 1981; Wilson and Hamilton 1996; Guzewich et al. 2013) and localized slope flows (Blumsack et al. 1973; Tyler and Barnes 2013; Rafkin et al. 2016) are important. On time-scales ranging from a few seconds to minutes, convective dust devils also induce measurable changes in surface pressure (Ellehoj et al. 2010; Kahanpää et al. 2016; Steakley and Murphy 2016). Next we show evidence of pressure variations caused by these systems.

Figure 3 (top) shows the daily mean atmospheric surface pressure measured during the VL1, VL2, MPF, PHX, and MSL missions as a function of solar longitude. To calculate representative daily mean surface pressure values at each site, we only use measurements taken on sols that have full diurnal coverage, resulting in 2245 sols at the VL1 site, 1050 sols at the VL2 site, 15 sols at the MPF site, 143 sols at the PHX site and 1096 sols at the MSL site. Of these five data sets, only the two VLs and the MSL have sufficient coverage to allow assessment of the annual repeatability of the pressure cycle. From MY 12 to MY 15, the interannual variability at the VL sites during the aphelion season was generally small (of the order of a few $\mathrm{Pa}$ ), while it increased significantly during the perihelion season (up to of tens of $\mathrm{Pa}$ ). This is particularly noticeable at the VL2 site during the northern winter $\left(L_{\mathrm{s}} \sim 280^{\circ}\right)$ in MY 12 (Fig. 3, top). The pressure increase was caused by a global dust storm (Fig. 2a), 
which intensified the tropical overturning circulation whose descending branch in the VL2 region caused such a pressure increase (Haberle et al. 1982; Wilson 1997). At the MSL landing site, a noticeable ( $\sim 15 \mathrm{~Pa})$ decrease in the mean surface pressure is observed during the mission (Fig. 3, top). This pressure decrease is mostly accounted for by the increase in altitude as the Curiosity rover has been moving uphill, climbing from about $-4520 \mathrm{~m}$ at the beginning of the operations to about $-4336 \mathrm{~m}$ on sol 1526, corresponding to the last MSL sol analyzed in this article. The good agreement between the predicted hydrostatic pressure decrease and the measurements (de la Torre-Juárez et al. 2016) suggests that the drift in the pressure is largely explained by changes in the rover elevation.

On seasonal time-scales, the variability of the daily mean surface pressure is large at each landing site, with two distinct minima and maxima per Martian year caused by the condensation and sublimation of the $\mathrm{CO}_{2}$ polar caps (Fig. 3, top). During the spring season in the southern hemisphere, parts of the southern polar cap sublimate and the released $\mathrm{CO}_{2}$ increases the atmospheric pressure with an annual maximum occurring at each landing site in late southern spring at $L_{\mathrm{s}} \sim 260^{\circ}$. Then, during the cold season in the southern hemisphere, the deposition of $\mathrm{CO}_{2}$ into the southern polar cap causes an annual minimum pressure in late southern winter at $L_{\mathrm{s}} \sim 150^{\circ}$. The relative minimum in late southern summer $\left(L_{\mathrm{s}} \sim 345^{\circ}\right)$ and relative maximum in late southern fall $\left(L_{\mathrm{s}} \sim 55^{\circ}\right)$ at each landing site are caused by the deposition and sublimation of $\mathrm{CO}_{2}$ into and from the northern polar cap.

The sol-to-sol variability at each landing site is relatively small during the aphelion season, but increases significantly during the perihelion season (northern autumn and winter) particularly at the VL2 site (Fig. 3, top). The larger sol-to-sol variability during the perihelion season is caused by baroclinic instability in autumn and winter, which generates perturbations in surface pressure that peak at the latitude of the polar jet stream (Barnes 1981). Since the VL2 site is closest to the high-latitude jet, the largest sol-to-sol variations occur at the VL2 site, followed by those at the VL1 (northern edge of the tropics) site, with the lowest variability in this sequence at the MSL site in the southern tropics. The six-toeight-sol oscillations observed by REMS are consistent with the periods observed at VL1 and VL2 (de la Torre-Juárez et al. 2014). Indeed, the consistent seasonal trend in sol-to-sol variability at VL2, VL1 and MSL is due to strong inter-hemispheric asymmetry in transient eddy activity forced by the inter-hemispheric asymmetry in topography (Barnes et al. 1993), with baroclinic activity strongly suppressed in southern high latitudes during southern autumn and winter (near aphelion). As the signature of northern storm activity traveling into the southern hemisphere has been seen in models and orbital imaging data (Wang et al. 2003), it is highly plausible that REMS is seeing their signature in Gale crater (Haberle et al. 2016).

Differences in the absolute values of the surface pressure measured by the various missions cannot be fully accounted for by differences in the elevation of the landing sites (Table 1). For instance, the surface pressure at the VL2 site $(-4.5 \mathrm{~km})$ during late autumn and early northern winter is significantly higher than at the MSL site ( $-4.4 \mathrm{~km})$ (Fig. 3, top). As explained by Haberle et al. (2014), this is due to the fact that temperatures are lower at the VL2 than at the MSL site for this season, and that elevation differences between the two hemispheres allow air to pool in the northern lowlands at the expense of air in the southern highlands. Thus, the pressure increases in the northern hemisphere and decreases in the southern hemisphere because of this orographic effect (see also Hourdin et al. 1993).

Figure 3 (bottom) shows the amplitude of the diurnal surface pressure variation as a function of solar longitude at each landing site. This amplitude (also called the diurnal atmospheric tide) is highly correlated to atmospheric dust opacity (Zurek and Leovy 1981; Bridger and Murphy 1998; Wilson and Hamilton 1996; Guzewich et al. 2016), with an 
Fig. 4 Diurnal evolution of the atmospheric pressure at the VLs, MPF, PHX and MSL landing sites at $L_{\mathrm{S}} \sim 145^{\circ}$, when pressure measurements were taken by each spacecraft (see Fig. 3). The hours-long periods of constant pressure in the Viking data are a consequence of the low resolution of the digitization of the data $(\sim 9 \mathrm{~Pa})$

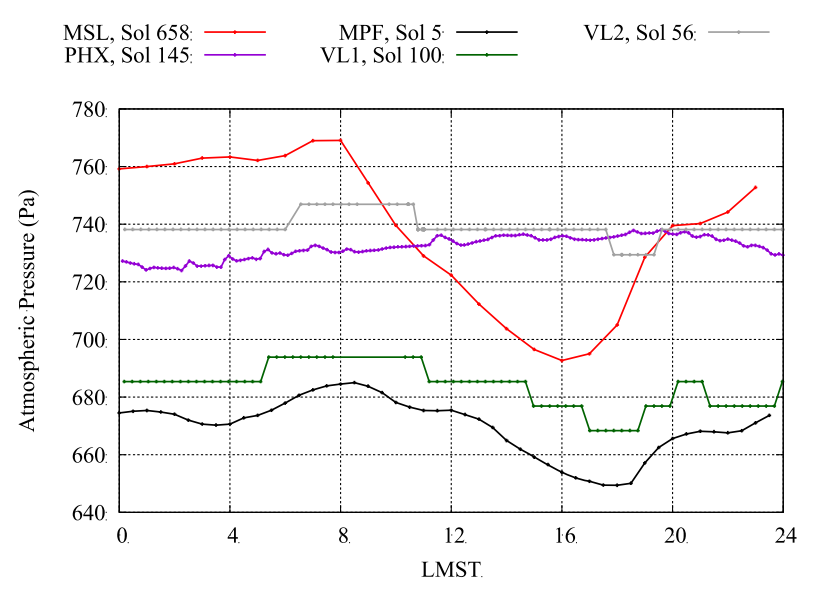

additional contribution from background seasonal cycles of the individual tide modes (e.g., the westward-propagating migrating diurnal tide and the eastward-propagating diurnal Kelvin wave). Therefore, the amplitude of the diurnal surface pressure variation is larger in the perihelion season (when dust activity is greater) than during the aphelion season (Fig. 3, bottom). Indeed, the amplitude of the diurnal surface pressure variation is largest at the VL1 and VL2 landing sites in MY 12 around $L_{\mathrm{s}} \sim 280^{\circ}$ (Fig. 3, bottom) when the atmospheric opacity is high because of a global dust storm (Fig. 2a).

The amplitude of the diurnal tide at the MSL site is larger than at the VL2 site throughout the year (Fig. 3, bottom), in spite of the similar elevation of the two sites. This occurs even during the aphelion season when dust opacity values are similar in both sites (Figs. 2a and 2g). This partly results from the fact that the thermal forcing of the diurnal tide is strongest at the equator, which also explains the small amplitude of the tides at the PHX site (Taylor et al. 2010). Its amplitude can be further enhanced by the interaction of eastward and westward propagating tidal modes (e.g., Wilson and Hamilton 1996). At the longitude of Gale crater this interaction is constructive and boosts the diurnal tidal amplitudes. However, the tides observed by Curiosity are much larger than those simulated by global models, even when accounting for these tidal interactions. As such, various researchers have suggested further enhancements at the Curiosity site by crater circulations (Haberle et al. 2014; Tyler and Barnes 2015), topographic variations in the zonal band (Rafkin et al. 2016), and a hydrostatic adjustment flow (Richardson et al. 2013).

Figure 4 shows the diurnal evolution of surface pressure at each landing site at $L_{\mathrm{s}}=145^{\circ}$, a seasonal date at which there is an overlap in data collected by all missions included in this study (Fig. 3, top). Except for the PHX mission, the daily maximum pressure value at each landing site occurs at around 08:00 LMST, with the daily minimum occurring between 16:00 and 18:00 LMST. The timing of these daily maxima and minima is strongly controlled by the superposition of the thermal tides. At the MSL site, the superposition of the diurnal and semidiurnal tidal components, whose phases are roughly consistent with those predicted by classical tidal theory (see Haberle et al. 2014), largely accounts for the timing of the observed maxima and minima. The fact that the other sites have the same timing suggests a similar superposition. However, interactions with the eastward propagating diurnal Kelvin mode, which is closest to resonance at this season (Zurek 1988), can complicate this simple picture. 
Fig. 5 Interannual and seasonal evolution of the daily mean near-surface air temperature (top) and the diurnal amplitude (difference between the daily maximum and minimum near-surface air temperature; bottom) at the VL1 (green colors), VL2 (gray colors), MPF (black), PHX (purple) and MSL (brown-red-orange) landing sites. MPF and PHX values correspond to measurements taken at $\sim 1.1 \mathrm{~m}$ and $\sim 2 \mathrm{~m}$ above the surface (furthest distance from the body of the landers), while VL1, VL2 and MSL values correspond to measurements taken at $\sim 1.6 \mathrm{~m}$
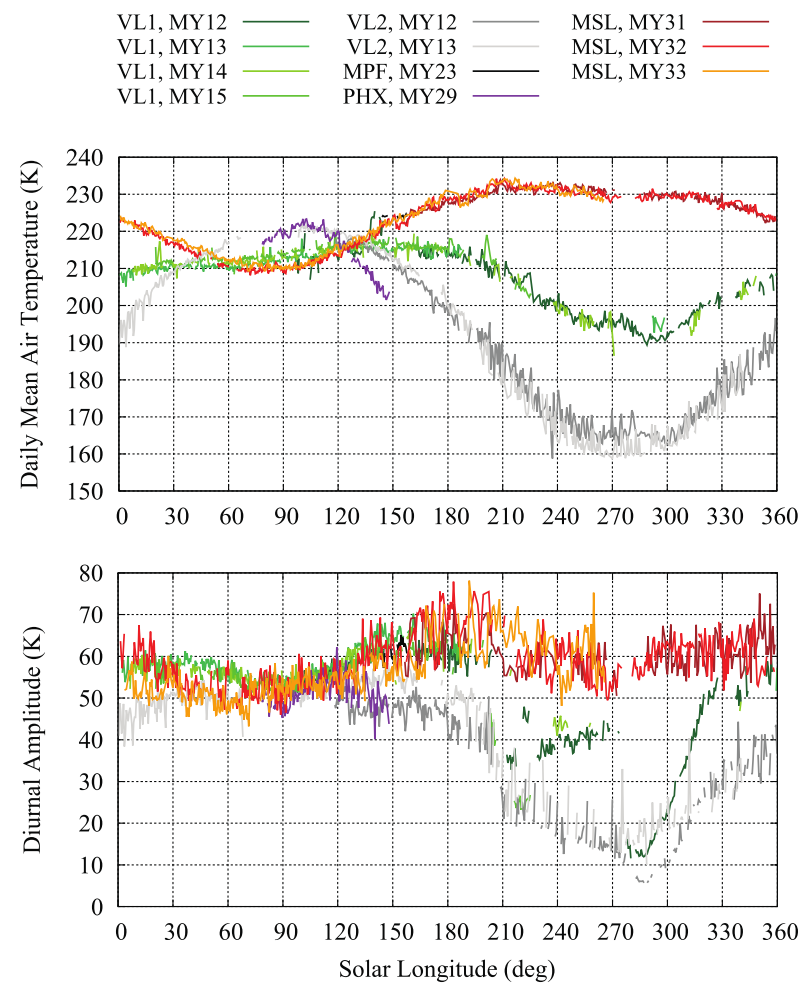

\subsection{Near-Surface Air Temperature}

In this section we analyze the seasonal and interannual variability of the near-surface air temperature at the VL, MPF, MER, PHX and MSL landing sites. Figure 5 (top) shows the daily mean air temperature at these sites as a function of solar longitude. Only measurements on sols with full diurnal coverage are used to calculate these daily mean air temperature values, resulting in 1201 sols at the VL1 site, 830 sols at the VL2 site, 15 sols at the MPF site, 143 sols at the PHX and 1323 sols at the MSL site. At the MPF and PHX sites, the daily mean air temperature is calculated at 1.27 and $2 \mathrm{~m}$ height above the surface, respectively, to minimize the effects of thermal contamination by the lander.

The interannual temperature variability at the VL1, VL2 and MSL sites is generally small during the aphelion season (of the order of a few Kelvin), while during the perihelion season it noticeably increases at the VLs sites (Fig. 5, top). This is particularly pronounced at the VL2 site between $L_{\mathrm{s}}=260^{\circ}$ and $300^{\circ}$ in MY 12 , when daily mean air temperatures were consistently larger than in MY 13 coinciding with a global dust storm (Fig. 5 top, gray colors). Since much less change in daily mean temperature is seen at VL1 during the storm (see also Ryan and Henry 1979), the increase at VL2 may be the result of an increase the downward infrared fluxes at the VL2 site during the storm. Large (20-30 K) increases in atmospheric temperatures (Martin and Kieffer 1979) associated with strong adiabatic warming in the downwelling branch of the overturning circulation (e.g., Haberle et al. 1982; Wilson 1997) would increase infrared emission to the surface possibly strongly enough to compensate for any decrease in solar insolation (which is small at this latitude and season). 
Consistent with the increase in the annual amplitude of surface solar insolation with latitude (Figs. $2 \mathrm{~b}$ and $2 \mathrm{~h}$ ), the seasonal variability of the daily mean air temperature is larger at the VL2 site than at the VL1 and MSL sites (Fig. 5, top), with the annual amplitude decreasing from $\sim 60 \mathrm{~K}$ at the VL2 site to $\sim 30 \mathrm{~K}$ at the VL1 and $\sim 20 \mathrm{~K}$ at the near-equatorial MSL site. The minimum annual temperature at the VL sites occurs during northern winter, between $L_{\mathrm{s}}=270^{\circ}$ and $300^{\circ}$ (Fig. 5, top), when the surface solar insolation presents an annual minimum (Fig. 2b), while the maximum annual temperature occurs in northern summer between $L_{\mathrm{s}}=120^{\circ}$ and $150^{\circ}$ at the VL1 site, and between $L_{\mathrm{s}}=90^{\circ}$ and $120^{\circ}$ at the VL2 site, when the surface solar insolation presents an annual maximum at both landing sites (Fig. 2b). Similarly, the maximum annual temperature at the MSL site coincides with the annual maximum in surface solar insolation around $L_{\mathrm{s}} \sim 210^{\circ}$ (southern spring), while the minimum annual value coincides with the annual minimum in surface solar insolation around $L_{\mathrm{s}} \sim 90^{\circ}$ (Figs. 5, top and 2h).

The sol-to-sol variability at each landing site is relatively small during the aphelion season, increasing moderately during the perihelion season particularly at the VL2 site (Fig. 5, top). As with the surface pressure, larger sol-to-sol variations during the perihelion season are caused by baroclinic eddies in the northern hemisphere during autumn and winter (Barnes 1980, 1981).

The daily mean air temperatures at the PHX site in Mars' Arctic were similar to those at the VL2 site between $L_{\mathrm{s}}=78^{\circ}$ and $125^{\circ}$ (Fig. 5, top), and larger than that at the VL1 site. The surface solar insolation at the PHX site is also similar to that at the VL2 and higher than at the VL1 site between $L_{\mathrm{s}}=78^{\circ}$ and $125^{\circ}$ (Figs. 2a and 2h). Similarly, daily mean air temperatures at the MPF site during most of the mission were slightly higher than those at the MSL site (Fig. 5, top), with the surface solar insolation at MPF site slightly higher than at the MSL site (Fig. 2h).

The diurnal amplitude of near-surface air temperature at the VL1, VL2, MPF, PHX and MSL sites is shown in Fig. 5 (bottom) as a function of solar longitude. The abrupt decrease in amplitude from $\sim 42$ to $\sim 12 \mathrm{~K}$ at the VL1 site around $L_{\mathrm{s}} \sim 275^{\circ}$ was caused by a dramatic increase in atmospheric opacity during the global dust storm occurred in MY 12 (Fig. 2a). At the VL2 site, the contemporaneous decrease in the diurnal amplitude of the air temperature was noticeable but much less pronounced than at the VL1 site because the surface solar insolation at the VL2 site is low at this time of the year (northern winter). Therefore, the increase in the atmospheric opacity does not decrease the diurnal amplitude of the air temperature significantly at this location. At the MSL site, the interannual and seasonal variability of the diurnal amplitude of near-surface air temperature is smaller than at the VL sites. This occurs because seasonal variability in solar insolation is small in the tropics and because there were no major dust storms during the observational period. The diurnal amplitude of the air temperature is similar at the MPF and PHX sites during the aphelion season when there is an overlap in date from the two missions (Fig. 5, bottom).

Observations with Mini-TES pointing downward were used to measure the ground and near-surface air temperature at $\sim 1.1 \mathrm{~m}$ for the MER-A first 1124 sols and the MER-B first 1110 sols. Since nighttime observations were rare at both landing sites, representative values of the daily mean air temperature at $\sim 1.1 \mathrm{~m}$ cannot be obtained. Instead, we show in Fig. 6 the diurnal evolution of $\sim 1.1 \mathrm{~m}$ air temperatures at the MER-A (top) and MER-B (bottom) sites as a function of the local mean solar time with variation in $L_{\mathrm{s}}$ shown using color code for MY 27 (the only year with complete annual coverage). For comparison with southernhemispheric MSL air temperatures, we also show the diurnal evolution of the air temperature at the MSL site at $L_{\mathrm{s}}=210^{\circ}$ ( $\mathrm{sol} \mathrm{103)}$ ) and $L_{\mathrm{s}}=83^{\circ}$ (sol 528) as solid lines, coinciding with the warmest and coldest periods at the MSL site (Fig. 5, top). At the MER-A site $\left(14.6^{\circ} \mathrm{S}\right)$, 
Fig. 6 Mini-TES near-surface $(\sim 1.1 \mathrm{~m})$ air temperature retrievals as a function of the local mean solar time (LMST) and $L_{\mathrm{S}}$ (color bar) for MER-A (top) and MER-B (bottom). For comparison, the diurnal evolution of air temperature during the warmest and coldest sols in the MSL mission are represented by color-coded lines (based on $L_{\mathrm{s}}$ )
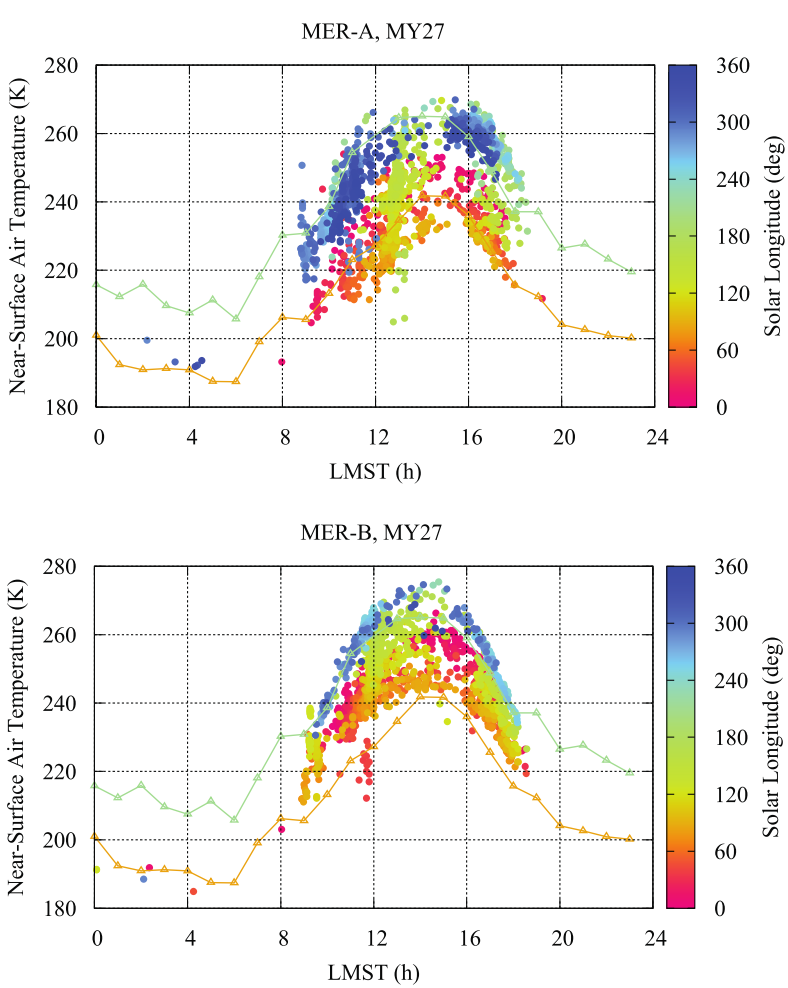

the annual amplitude of surface solar insolation is larger than at the MSL $\left(4.6^{\circ} \mathrm{S}\right)$ due to its location further from the equator, resulting in warmer daytime temperatures during the annual warmest season and colder daytime temperatures during the annual coldest season than at the MSL site (compare orange and green lines with solid circles of the same color in top panel of Fig. 6). It is interesting to note that temperatures in the range 200-220 K between 12:00-14:00 LMST (see isolated green dots corresponding to $L_{\mathrm{s}} \sim 171^{\circ}$ in top Fig. 6), were retrieved during a regional dust storm that raised the atmospheric opacity values from 0.6 to 1.4 in the span of a few sols (see Fig. 2 c, MY 27; $L_{\mathrm{s}} \sim 170^{\circ}$ ), causing these lower daytime temperatures. At the MER-B site $\left(1.9^{\circ} \mathrm{S}\right)$, the values and annual range of the surface solar insolation are similar to those at the MSL site (Figs. $2 \mathrm{f}$ and $2 \mathrm{~h}$ ). Indeed, at the MER-B site the air temperature at $\sim 1.1 \mathrm{~m}$ stays approximately within the limits of MSL's warmest and coldest sols (Fig. 6, bottom).

\subsection{Ground Temperature}

The values and variability of ground temperature are mainly governed by the surface radiation budget, which depends on the time of year, location, atmospheric opacity, and the thermal and physical properties of the terrain. In this section, we analyze the diurnal, seasonal and interannual variability of ground temperature at the MER, PHX and MSL sites.

Among the MER, PHX and MSL missions, only MSL conducted full diurnal measurements of ground temperature. Figure 7 shows the daily mean, maximum, and minimum ground temperature during the first 1526 sols (MY 31-33) of the MSL mission as a function of solar longitude. To calculate these temperatures, we use only the REMS Ground 
Fig. 7 Interannual and seasonal evolution of the daily maximum, mean and minimum ground temperature at the MSL landing site. Only the MSL mission provides temporal coverage good enough to show interannual and seasonal evolution of $T_{g}$

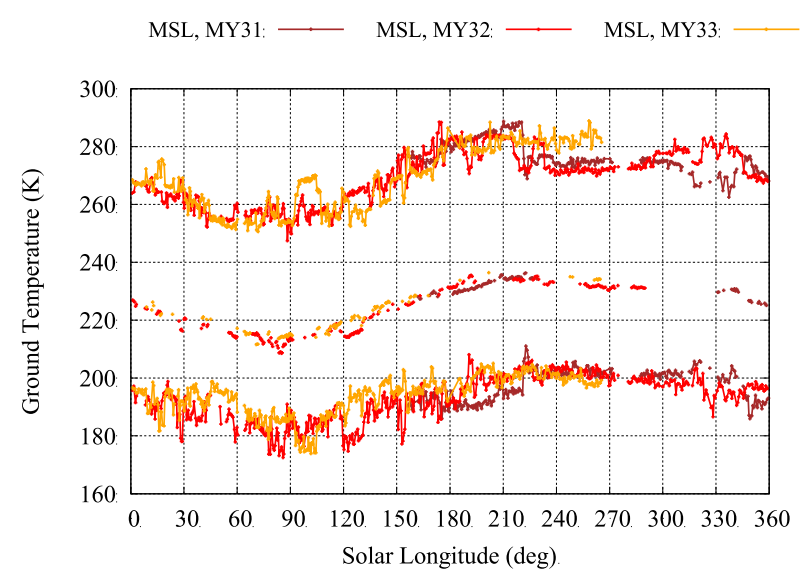

Temperature Sensor (GTS) data with the highest confidence possible, that is, with the ASIC power supply in its operation range, the highest recalibration quality and with no shadows in the GTS field of view (see Hamilton et al. 2014 for details on GTS uncertainties) from measurements on sols with full diurnal coverage (resulting in 413 sols).

The interannual variability of the daily mean ground temperature at the MSL site is small, of the order of a few Kelvin (Fig. 7). This occurs in spite of the measurements being acquired in different locations as the rover traversed Gale crater. Small variations could be caused by changes in the albedo of the surface along the traverse, which range from 0.1 on sandy terrains to 0.3 on mudstone (Vasavada et al. 2017). The seasonal variability of the daily mean ground temperature is also small at the MSL site, with an annual amplitude of about $20 \mathrm{~K}$ (Fig. 7). The minimum annual temperatures occur during late fall at $L_{\mathrm{s}} \sim 85^{\circ}$ (Fig. 7), when the surface solar insolation is the smallest (Fig. 2h), whereas the maximum annual values occur during spring at $L_{\mathrm{s}} \sim 210^{\circ}$, when the surface solar insolation is the largest.

The diurnal amplitude of ground temperature at the MSL site is primarily governed by the type of terrain, and in particular by its thermal inertia $(I)$. Terrains with low thermal inertia experience higher daytime maximum temperatures and lower nighttime minimum temperatures than terrains with higher thermal inertia. As an example, the sudden decrease in the diurnal maximum ground temperature (and increase in the diurnal minimum temperature) which occurred at $L_{\mathrm{s}} \sim 220^{\circ}$ in MY 31 (Fig. 7) coincided with Curiosity's traverse from a terrain with $I \sim 300 \mathrm{~J} \mathrm{~m}^{-2} \mathrm{~K}^{-1} \mathrm{~s}^{-1 / 2}$ to a terrain (Yellowknife Bay) with $I \sim 420 \mathrm{~J} \mathrm{~m}^{-2} \mathrm{~K}^{-1} \mathrm{~s}^{-1 / 2}$ (Martínez et al. 2014). During this traverse (around sol 120), dust opacity values barely changed and thus neither did the surface solar insolation. Indeed, Vasavada et al. (2017) used ground temperature measurements and modeling to calculate the thermal inertia at the MSL site, obtaining values ranging from about 170 to $550 \mathrm{~J} \mathrm{~m}^{-2} \mathrm{~K}^{-1} \mathrm{~s}^{-1 / 2}$ in the first 1250 sols of the mission. The differences in terrain traversed by the Curiosity likely account for the variability of the diurnal amplitude of ground temperature.

Changes in atmospheric opacity also regulate the amplitude of variations in ground temperature (e.g. Määttänen and Savijärvi 2004). For a given type of terrain, lower atmospheric opacity causes higher daytime maximum temperatures and lower nighttime minimum temperatures and vice versa (same as with thermal inertia). This occurs because aerosols like dust scatter and absorb solar radiation, reducing the insolation at the surface. At night, downward infrared emission from aerosols warms the ground. However, the impact of variations in atmospheric opacity on the amplitude of the ground temperature has been very small at 
Fig. 8 Mini-TES and Phoenix/TECP surface temperature measurements for MER-A (top), MER-B (middle) and Phoenix (bottom) landing sites. For comparison, we represent the diurnal evolution of ground temperature during the warmest and coldest sols in the MSL mission by color-coded lines (based on $L_{\mathrm{S}}$ )
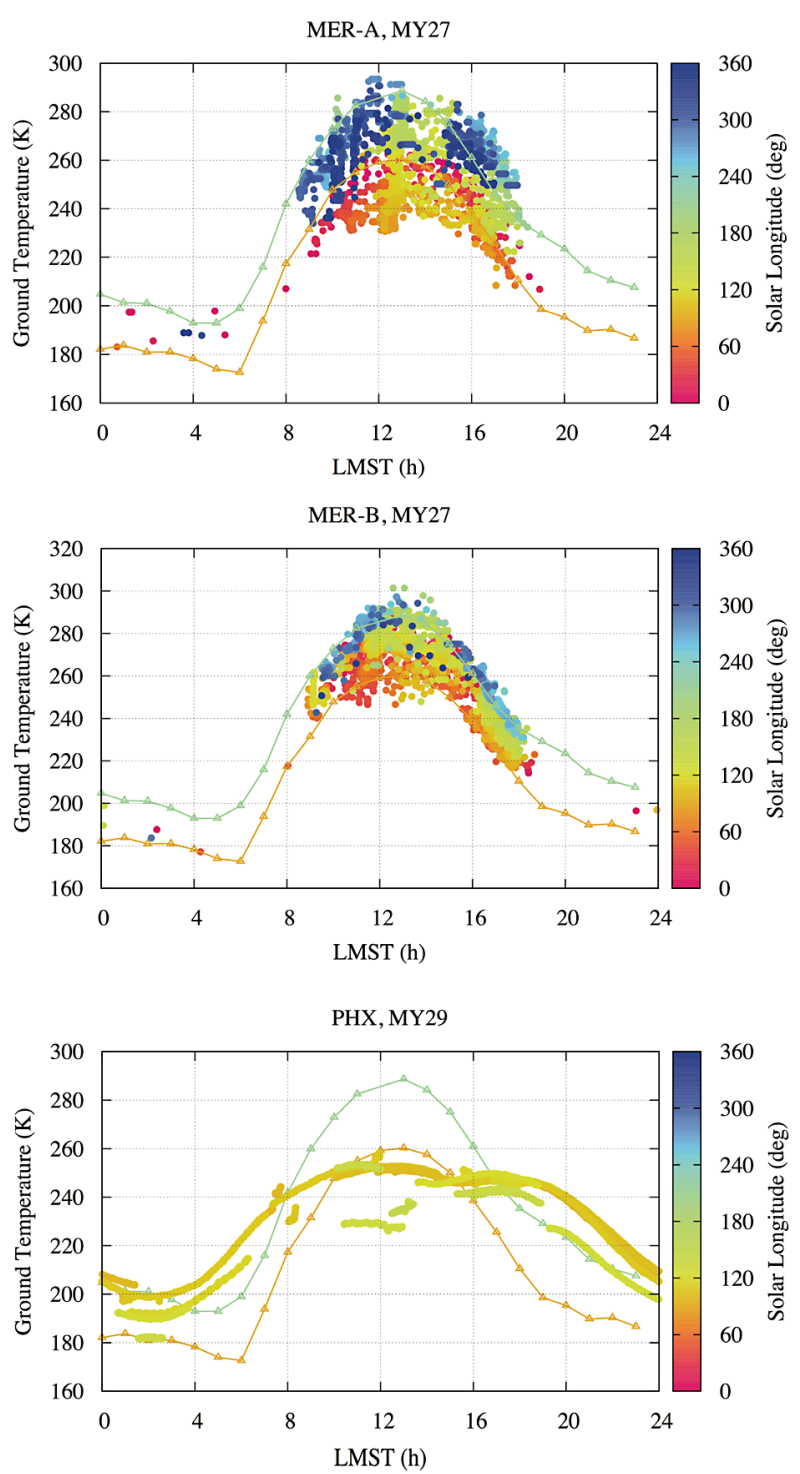

Gale crater compared with that of changes in thermal inertia. For instance, the sudden increase in atmospheric optical depth in MY 31, from $\sim 0.6$ at $L_{\mathrm{s}}=200^{\circ}$ to $\sim 1.2$ at $L_{\mathrm{s}} \sim 208^{\circ}$ (Fig. 2g) was not followed by a decrease in the daily maximum ground temperature (Fig. 7). Instead, the daily maximum ground temperature kept increasing until $L_{\mathrm{s}} \sim 220^{\circ}$, when the rover reached a terrain with much higher thermal inertia (Martínez et al. 2014).

As for the near-surface air temperature discussed in Sect. 3.3, we show in Fig. 8 the diurnal evolution of ground temperature at the MER-A (top), MER-B (middle) and PHX (bottom) sites as a function of the local mean solar time with variation in $L_{\mathrm{s}}$ during MY 27 shown as colors at the MER sites, and in MY 29 at the PHX site. For the sake of comparison, we also show in Fig. 8 the diurnal evolution of the ground temperature at the MSL site at $L_{\mathrm{s}}=210^{\circ}$ (sol 103) and $L_{\mathrm{s}}=86^{\circ}$ (sol 534) in solid lines, coinciding with the warmest 
and coldest periods at the MSL site (Fig. 7). MER-A's further distance from the equator and larger annual amplitude of surface solar insolation than those of the MSL site result in significantly lower daytime temperatures at $L_{\mathrm{s}} \sim 86^{\circ}$ and slightly greater daytime temperatures at $L_{\mathrm{s}} \sim 210^{\circ}$ (Fig. 8, top). At the MER-B site, where the surface solar insolation is comparable to that at the MSL, ground temperature values stay to a very good extent within the limits marked by MSL's warmest and coldest sols (Fig. 8, middle).

The PHX/TECP instrument was used to measure the soil temperature during 16 sols, with sporadic diurnal coverage on each of these sols. Since the coupling of the TECP needles with the regolith was insufficient (Zent et al. 2010), and the TECP needles are $15 \mathrm{~mm}$ in length, the measured temperature represents an integrated temperature over the top $15 \mathrm{~mm}$ of the subsurface rather than surface skin temperature of the regolith. Figure 8 (bottom) shows the complete set of TECP soil temperature measurements. The daytime maximum temperature of $\sim 259 \mathrm{~K}$ was achieved on sol 71, coinciding with the highest value of surface solar insolation during PHX operations at $L_{\mathrm{s}} \sim 107^{\circ}$ (Fig. 2h). As the mission progressed and the surface solar insolation declined (Fig. 2h), temperatures quickly decreased, with daytime maximum values of only $\sim 230 \mathrm{~K}$ and nighttime minimum values as low as $\sim 180 \mathrm{~K}$ at $L_{\mathrm{s}} \sim$ $133^{\circ}$ on sol 122 (the last sol with nighttime measurements). The local minimum between 13:00 and 14:00 LMST is caused by shadows of different parts of the PHX spacecraft on the surface.

\subsection{Near-Surface Wind Speed and Direction}

Of all quantities discussed here, wind speed and direction are most strongly influenced by the local and regional topography. In addition, they also depend on the surface radiation budget and large-scale variation in atmospheric opacity, via their impact on the global overturning circulation, atmospheric tides and baroclinic/barotropic waves, among other processes. The extent to which each dominates the cycles of wind depends on the instrument's locationand for topography, its precise location, since moving only a few meters can significantly impact the wind provided that the local topography changes dramatically (Newman et al. 2017). It is worth noting that the VLs, MPF and PHX all landed on smooth, gently sloping plains in the northern hemisphere, largely due to entry-descent-landing (EDL) safety constraints. In such regions, the influence of thermal tides and regional slopes would be expected to dominate the diurnal variation of wind, at least in periods without significant wave activity (such as local summer in the northern hemisphere). By contrast, the landing system used for MSL was more sophisticated and permitted landing inside a $\sim 155 \mathrm{~km}$-diameter crater, hence the topography around MSL is more extreme than at any previous site and strongly dominates in most seasons. In this section we analyze the diurnal, seasonal, and interannual variability of wind speed and direction at the VL, PHX and MSL sites.

Figure 9 shows the variation of the daily minimum and maximum wind speed as a function of season at the VL1 (up to sol 44, when the hot wire heater failed), VL2, and PHX sites. The daily mean wind speed is also shown for the VL sites. The VL2 dataset shows the most complete seasonal data set, and demonstrates the strong dependence of wind speed on global and regional rather than local forcing at this site. Wind speeds are lowest during northern hemisphere spring and summer $\left(L_{\mathrm{s}} \sim 10^{\circ}\right.$ to $\left.190^{\circ}\right)$, despite solar insolation at the VL2 site peaking during this period (Fig. $2 \mathrm{~b}$ ). The processes dominating wind speed variation at the relatively high northern latitude of $\operatorname{VL} 2\left(47.9^{\circ} \mathrm{N}\right)$ are twofold: (i) the global circulation and (ii) wave activity. The global circulation is much stronger in northern fall and winter due to the stronger heating around southern summer solstice (due to Mars's large eccentricity and the timing of perihelion), the topographic dichotomy (which tends to enhance a Hadley 


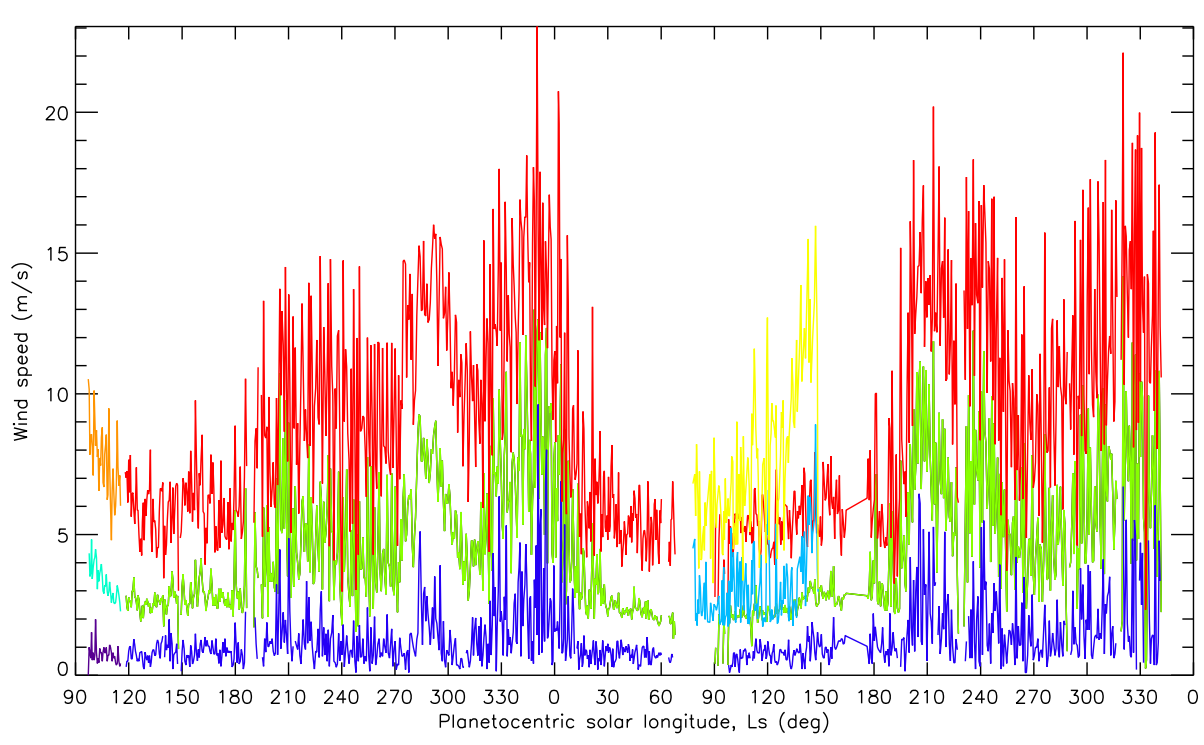

Fig. 9 Minimum (dark blue), mean (green), and maximum (red) daily wind speed at the VL2 site at a function of $L_{\mathrm{S}}$ in MY 12 and 13. Also shown is the minimum (purple), mean (cyan), and maximum (orange) daily wind speed at the VL1 site over the first 44 sols of its mission in MY 12 (see left hand side of the figure), and the minimum (light blue) and maximum (yellow) daily wind speed at the PHX site in MY 29. Note that the VL minimum and maximum values are calculated using the $1 / 25$ th of a sol binned dataset, thus do not correspond to the smallest and largest individual winds measurements. The PHX values shown do correspond to individual measurements; however, the range of local times covered varied over the period shown, thus these data contain inherent bias

circulation with rising motion in the south), and the dust feedback (with the higher winds causing more dust lifting, which in turn causes more radiative heating, which in turn causes a stronger circulation). Baroclinic waves produced by the strong thermal contrasts around the northern seasonal polar cap's edge, which are strongest in northern fall through early spring, cause wind speeds to peak during northern fall and winter in both VL2 years. This also likely explains the gradual increase in wind speed throughout the even higher northern latitude PHX mission.

The second VL2 year presents a drop in wind speed in the middle of the fall/winter period, around perihelion $\left(L_{\mathrm{s}} \sim 251^{\circ}\right)$ and solstice. This is known as the 'solsticial pause' (e.g., Lewis et al. 2016) and its cause is not well understood. By contrast, the same period in the first year of VL2 shows only a slight drop in wind speed before a rapid increase begins at about $L_{\mathrm{s}}=270^{\circ}$. In addition, the period from $L_{\mathrm{s}}=270^{\circ}$ to $L_{\mathrm{s}}=320^{\circ}$ during the first year of VL2 exhibits far less sol-to-sol variability than the rest of the fall/winter seasons. This is due to the presence of the large 1977b global dust storm over this exact period, as shown by the increase in VL1 and (to a lesser extent) VL2 opacities in Fig. 2a. While the impact of the earlier 1977a storm (at about $L_{\mathrm{s}} \sim 220^{\circ}$ ) is less clear, the dust-storm-induced enhancement and broadening of the global circulation during the $1977 \mathrm{~b}$ storm clearly extends out to VL2 latitudes, producing a noticeable increase in daily mean, maximum and minimum wind speeds. Again, this demonstrates the global and regional rather than local scale response of winds to change in dust loading and hence radiative forcing. The local opacities at the VL2 site are slightly higher during the earlier storm, which would suggest it should have the greatest effect if local forcing dominates. Instead, it is the global scale changes in dust 
loading (and hence circulation) that dominate and produce a far greater impact due to the later storm, which had the higher dust opacities planet-wide (as shown by the peak in VL1 dust loading, for example). The reduction in sol-to-sol variability reflects the suppression of baroclinic wave activity at VL2 during the 1977b storm (Barnes 1980).

Wind direction may vary through a full $360^{\circ}$ over a sol, thus the mean value (or maximum and minimum) is usually difficult to interpret and potentially misleading. For this reason we only show wind direction as diurnal variation at selected times of year, rather than trying to show a mean value or range as a function of season. Figures 10 and 11 show respectively the wind speed and wind direction as a function of local time over several sols at one time of year at the VL1 site, at six times of year (including two examples of the same season in different years) at the VL2 site, at one time of year at the PHX site, and at the MSL site during the Bagnold Dunes wind characterization investigation. Figure 12 shows the same information, but now averaged over the sols shown in Figs. 10 and 11 for each site, and plotted in the form of hodographs. In general, wind speeds peak during the daytime at all landing sites and seasons displayed, likely because of mixing by convectively-forced turbulence. Exceptions are at the VL2 site at $L_{\mathrm{s}} \sim 195^{\circ}$ (Figs. 10b and f), where peak wind speeds occur at $\sim 21: 00$ in some sols, and at $L_{\mathrm{s}} \sim 285^{\circ}$ during the $1977 \mathrm{~b}$ global storm (Fig. 10c), as discussed further below. The greatest VL2 wind speeds occur in the $L_{\mathrm{s}}=345^{\circ}$ plot (Fig. 10d), late in the northern winter period discussed above, which contains some of the highest wind speeds measured on Mars. The lowest wind speeds occur in the VL2 $L_{\mathrm{s}}=105^{\circ}$ plot (Fig. 10e), during northern summer.

The low interannual variability in both wind speed and direction during the equinoctial season $\left(L_{\mathrm{s}}=195^{\circ}\right)$ at the VL2 site can be seen by comparing plots (b) and (f) in Figs. 10-12. Shortly after northern winter solstice at $L_{\mathrm{s}}=285^{\circ}$, however, there is significant year-to-year variability, as shown by comparing plots (c) and (g). The first year has stronger peak winds, a different time of peak wind occurrence (shortly after sunrise and sunset at 07:00 and $\sim 20: 00$, rather than at $\sim 15: 00$ as occurs in the second year) and also far more sol-to-sol repeatability. The wind direction is also more westerly than northerly in the first year than in the second. These major year-to-year difference are due to the presence of the global $1977 \mathrm{~b}$ dust storm in the first year, which strengthened the large-scale circulation, altered the relative amplitude of different tidal modes, and reduced the contribution of high-latitude frontal winds to the pattern here. From sol to sol, the wind direction is most repeatable at $L_{\mathrm{s}}=105^{\circ}$ at both VL sites (Fig. 11a and 11e), but appears to be most variable from sol to sol at the PHX site at the same season (Fig. 11h), most likely due to the strong influence of baroclinic waves at this high latitude. Wind directions at the MSL site during the Bagnold Dunes wind characterization investigation are also rather repeatable from sol to sol, most likely due to the strong topographic control (described below).

Figure 12 demonstrates that, for all landing sites and seasons other than MSL, the wind direction exhibits continuous turning over the majority of each sol. At the VL1 site there is predominantly anti-clockwise turning from 22:00 to 16:00, with southeasterlies turning to strong southwesterlies by late morning, then back to southeasterlies again. By contrast, there is predominantly clockwise turning at the VL2 site in all seasons shown. This is likely due to the different phasing of the tides relative to the background circulation and the stronger Coriolis effect at the higher latitude of VL2 (e.g. Haberle et al. 1993b). The wind turns clockwise through a full $360^{\circ}$ in some seasons $\left(L_{\mathrm{s}} \sim 345^{\circ}\right.$ and $105^{\circ}$, Figs. $12 \mathrm{~d}$ and e). MPF wind direction data are not shown here, but wind direction as a function of time of day for 30 sols following $L_{\mathrm{s}}=142^{\circ}$ was presented in Fig. 6 of Schofield et al. (1997). The MPF winds also turned clockwise through a full $360^{\circ}$ rather steadily and very repeatedly throughout these sols, which might suggest that they were largely controlled by tidally-induced flow 

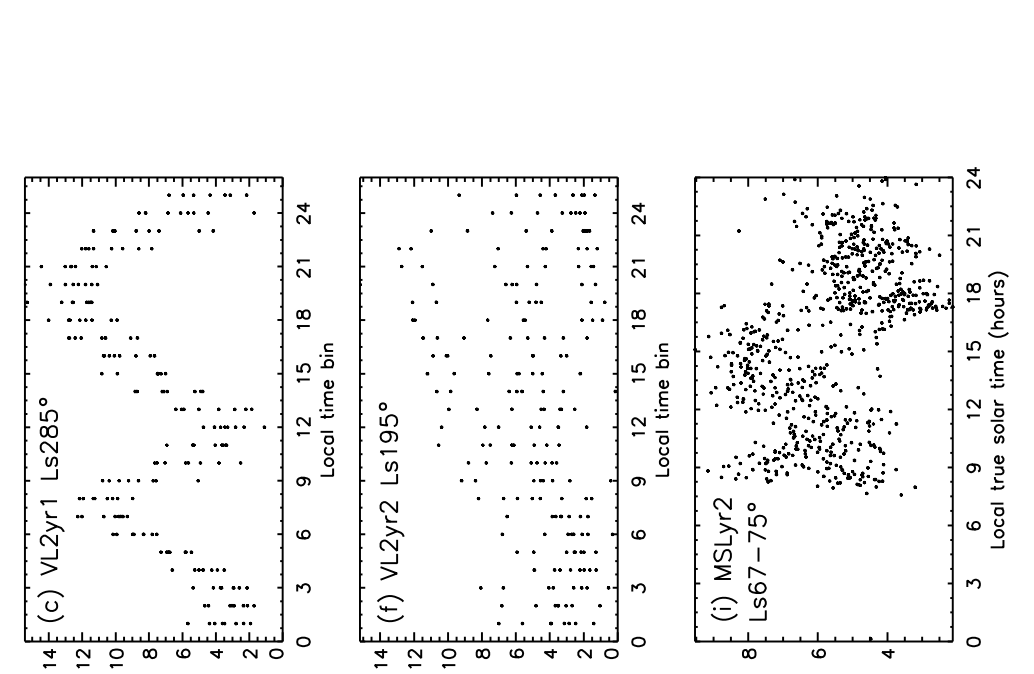

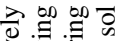

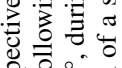

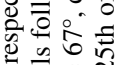
bo

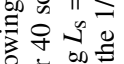

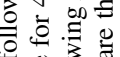

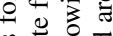

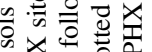

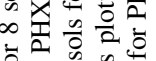

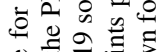

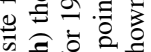
क

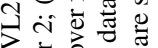

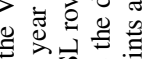

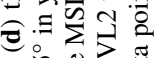

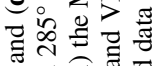
웡요 已 击可品 อำ行

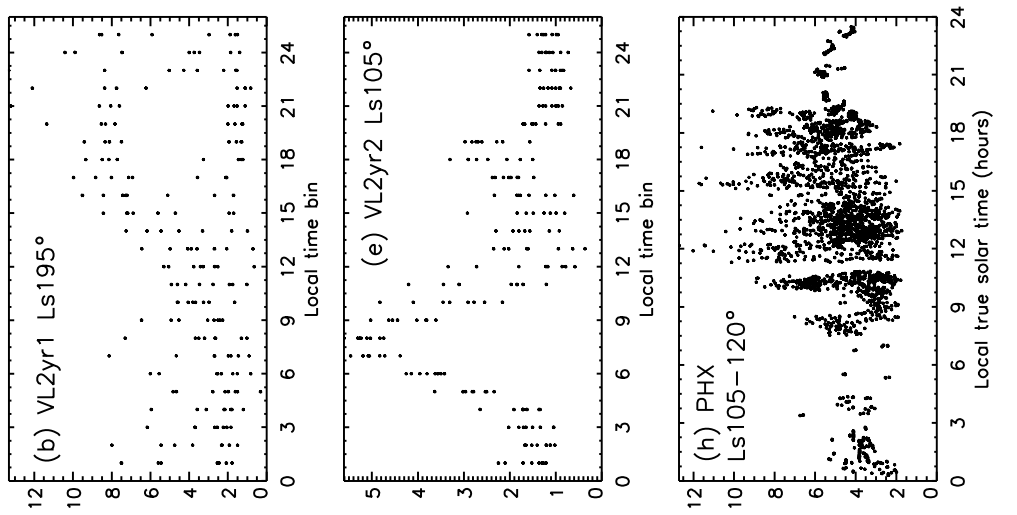

ํํㅇํㅇㅎㅠ

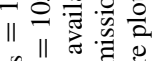

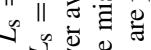

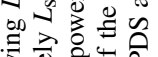

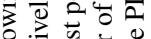
응 矛芯导 a के 我

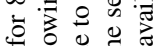
응 :

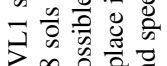
$>\infty$ 它

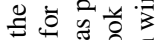
ฮิ.

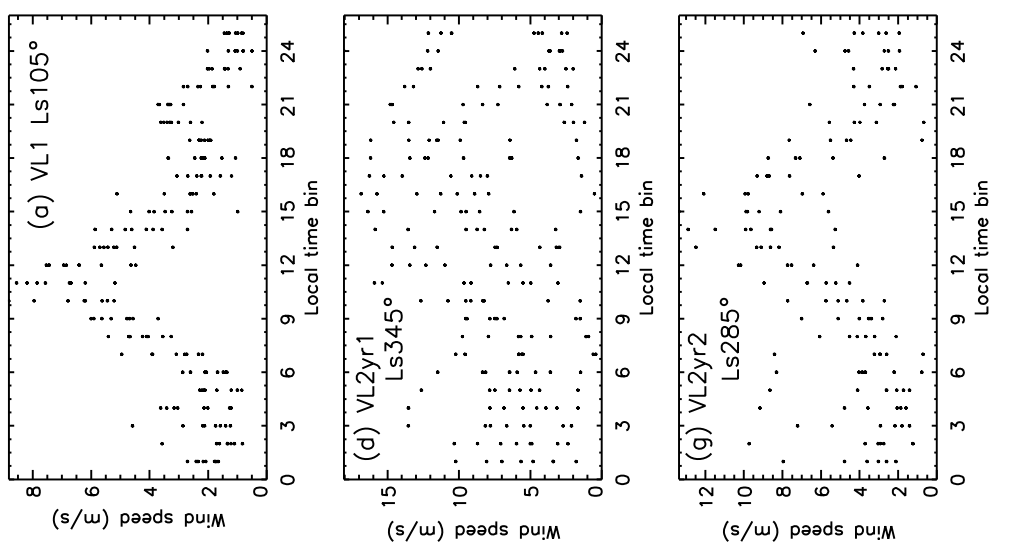

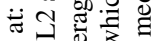
安分范方

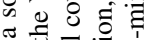

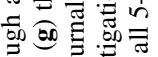

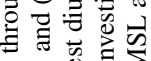
\& $\Theta$ 包募.

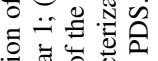

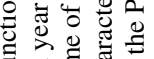

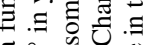
o in

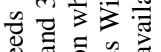
ठै.

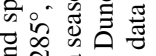

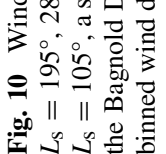



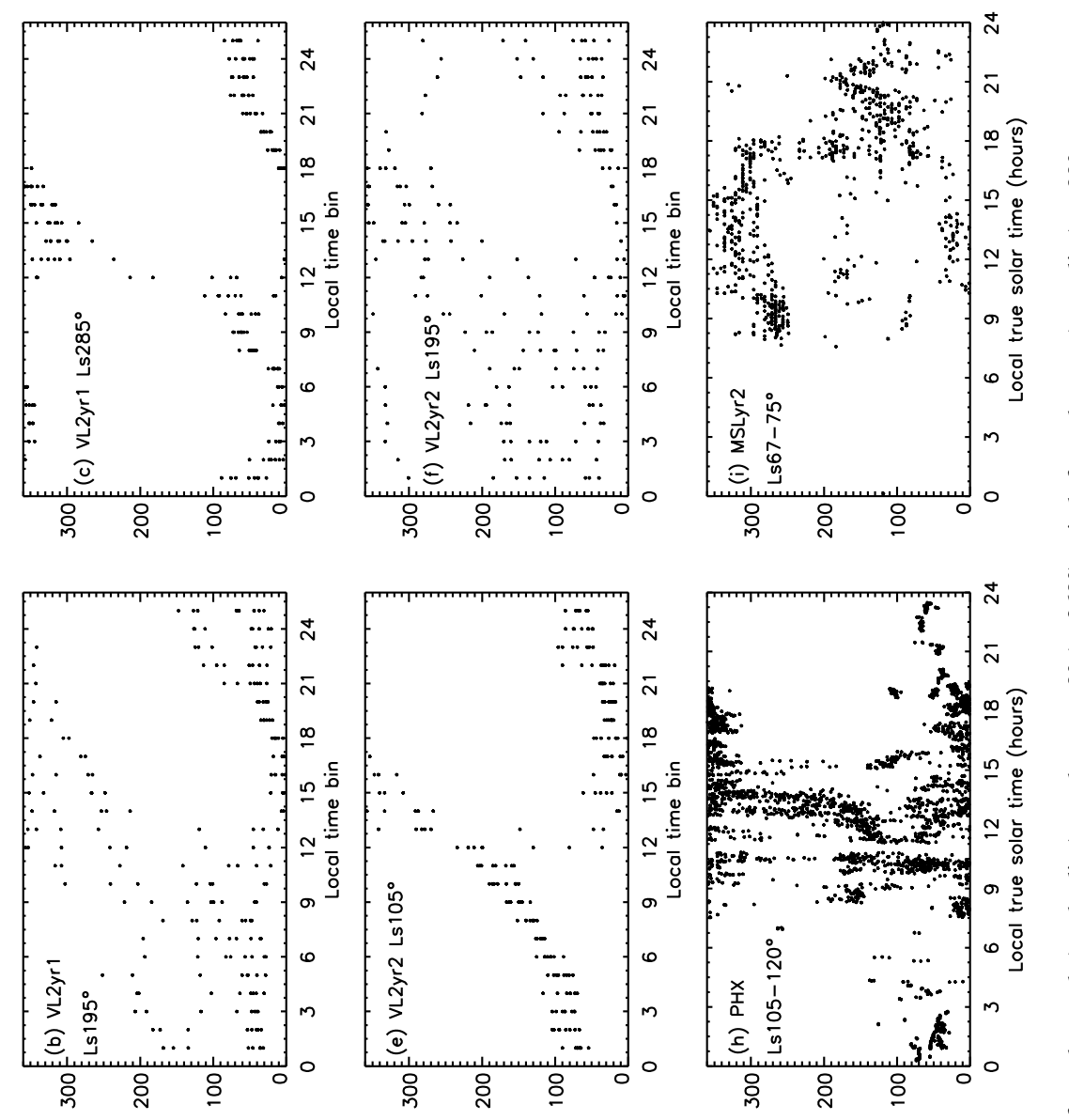

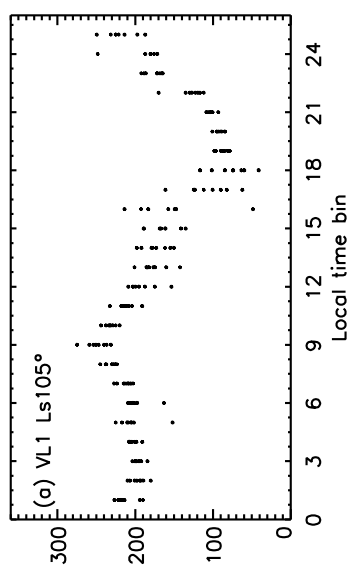

(6әр) ио!ґวаנ!р pu!M

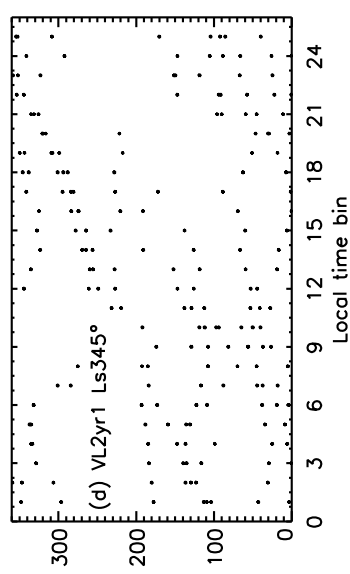

(Бәр) ио!јวәљ!р pu!M

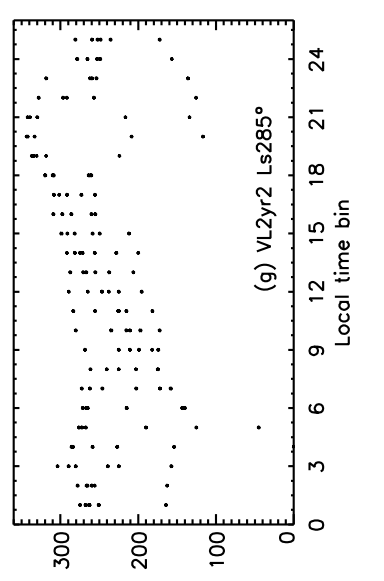

(бар) ио!ґวәл!р pu!M

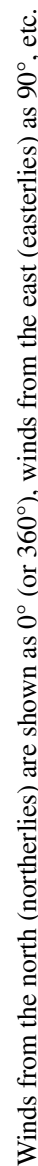

获 

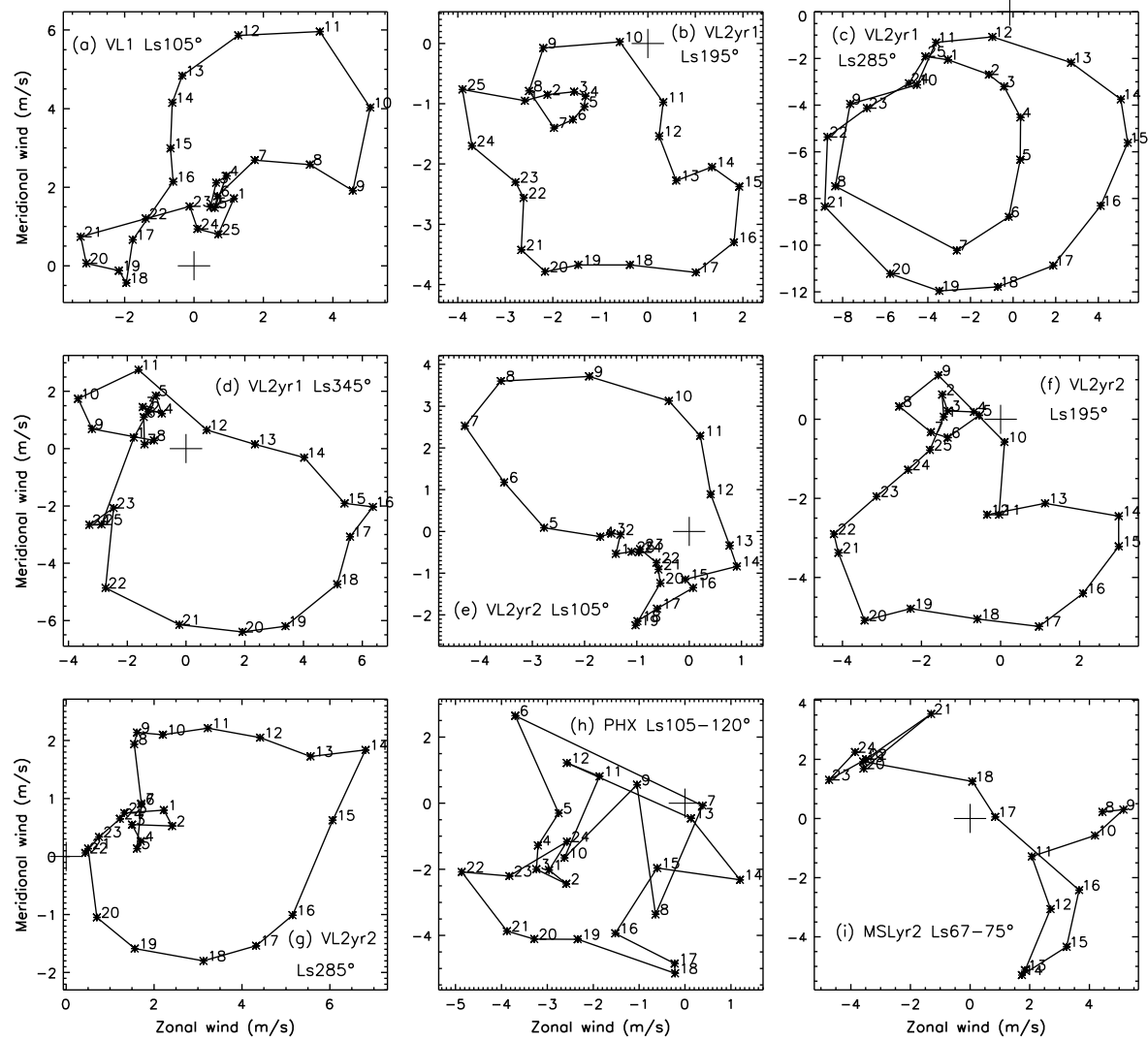

Fig. 12 As in Fig. 11 but now hodographs showing the wind speed and direction averaged over all sols for each case. For the VL sites (a-g) the times indicated are the 25 times of sol available in the binned dataset, whereas for PHX and MSL the times indicate local true solar time. The mean wind vector at each time is given by a vector pointing from the cross (indicating 0,0 ) to the asterisk corresponding to that time

of mass at this relatively flat, near-equatorial landing site. However, the phasing is inconsistent with this explanation, suggesting either that the tidal forcing in this region is more complex or that the flow is more affected by slope winds. Indeed, southerly or southeasterly winds appear to dominate overnight, which is consistent with downslope winds related to the regional topography. The situation at PHX is more complex but seems to show clockwise turning overall. By contrast, at MSL winds are dominated by topographic flows at the season shown (late southern fall), due to its location on the NW slope of Aeolis Mons, the large central peak inside Gale Crater. As demonstrated by Figs. 11 and 12i, there is a clear transition from upslope winds during the day (from the NW/N, $\sim 270$ to $360^{\circ}$ ) to downslope winds during the night (from the SE, $\sim 135^{\circ}$ ), with only short periods of rapid turning in between (e.g. from $\sim 16: 30-18: 30$ ).

\subsection{Near-Surface Relative Humidity and Water Vapor Content}

Of all spacecraft landed on Mars, only the PHX and MSL carried sensors to measure the near-surface relative humidity (Table 1) (Zent et al. 2009; Gómez-Elvira et al. 2012). For 


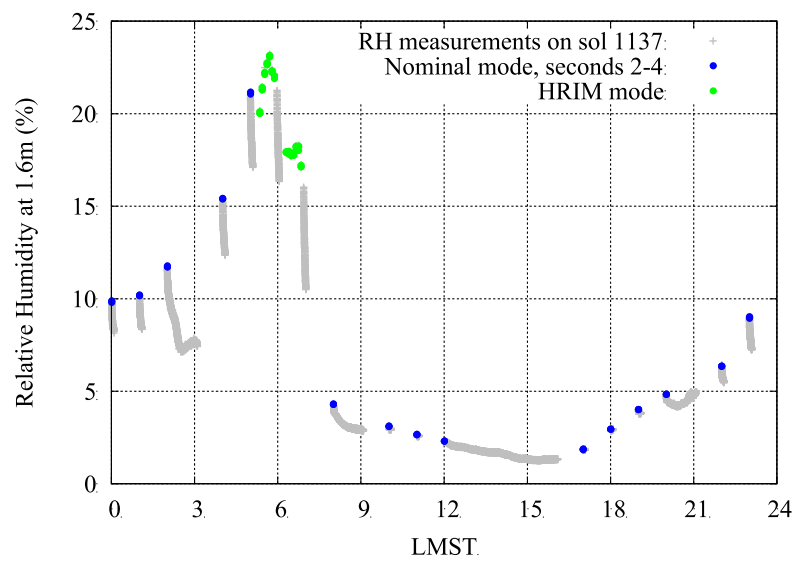

Fig. 13 Example of REMS RH measurement strategy on sol $1137\left(L_{\mathrm{S}} \sim 56^{\circ}\right)$. The complete set of RH values is represented in gray, while RH values with the highest confidence are represented in blue and green. Values in blue correspond to measurements obtained in the nominal mode (first five minutes of every hour), but only during seconds 2, 3 and 4 after the RH sensor has been turned on after $\sim 5$ min of inactivity. Values in green correspond to measurements obtained during seconds 2, 3 and 4 in the high-resolution interval mode (HRIM), which consists of alternately switching on and off the sensor at periodic intervals to minimize heating. $\mathrm{RH}$ values rapidly decrease due to spurious effects of heating

the PHX mission, only the raw output of the TECP RH sensor (unprocessed RH values) is available in the NASA PDS because of uncertainties in pre-flight instrument calibration. The calibration function was revised in 2016 to correct for inaccuracies at the lowest temperatures encountered at the PHX landing site (Zent et al. 2016), but the new processed RH values are not available in the PDS yet. For the MSL mission, processed RH values retrieved using the latest recalibration parameters (August, 2016) are available for two full Martian years.

Among the full set of REMS RH measurements, only those taken during the first four seconds after the RHS has been turned on after at least $\sim 5$ min of inactivity are considered here. After four seconds, the local RH values are affected by the heating effect of the sensor and the local RH measured by the sensor significantly departs from the actual $\mathrm{RH}$ of the atmosphere (Sect. 2.5). Reliable values include RH measurements taken during the nominal and the so-called high-resolution interval mode (HRIM), which consists of alternately switching the sensor on and off at periodic intervals to minimize heating and is only used on selected one to two hour observation blocks. As an example, Fig. 13 shows in gray the complete set of RH measurements made on sol $1137\left(L_{\mathrm{s}} \sim 56^{\circ}\right)$, with $\mathrm{RH}$ values with the highest confidence highlighted in green (HRIM mode) and blue (nominal mode).

Using REMS RH measurements selected as described above, we show in the Fig. 14 (top) the interannual and seasonal variability of the daily maximum $\mathrm{RH}$ value during the first 1526 sols of the MSL mission. REMS-derived values of VMR, calculated as $V M R=R H \times e_{s}(T) / P$ using the daily maximum $\mathrm{RH}$ value and simultaneous measurements of temperature and pressure, where $e_{s}$ is the saturation vapor pressure over ice, are shown in Fig. 14 (bottom). The daily maximum RH generally occurs between 04:00 and 06:00 LMST throughout the year, and thus VMR values shown in Fig. 14 (bottom) represent nighttime estimates. Daytime REMS-derived VMR values present large uncertainties because of the extremely low RH (with daytime values $<5 \%$ between 10:00 and 18:000 LMST throughout 
Fig. 14 (Top) Interannual and seasonal evolution of the daily RH during the first 1258 sols of the MSL mission (MY 31-33). The daily maximum $\mathrm{RH}$ is generally achieved between 04:00 and 06:00 LMST, with daytime values staying below $5 \%$ between 10:00 and 18:00 LMST throughout the mission. (Bottom) Interannual and seasonal evolution of the most accurate VMR value per sol at the MSL landing site. This value is obtained at the same time as the RH shown above
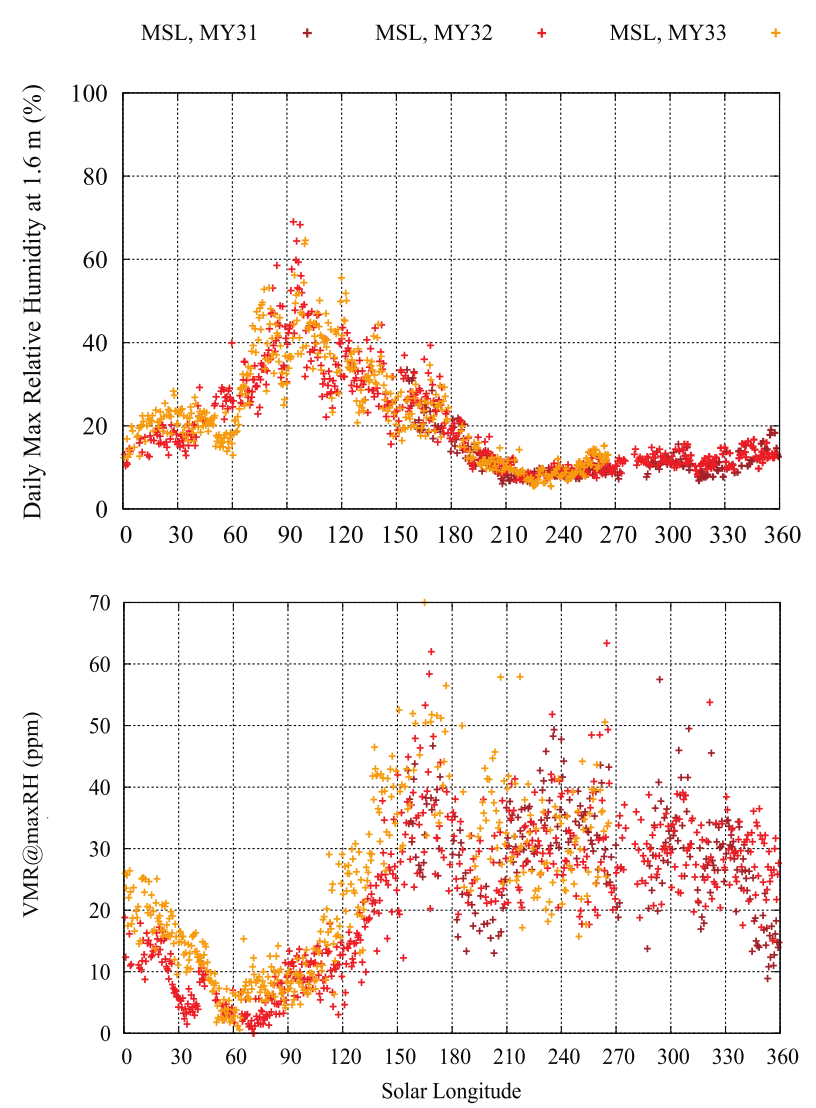

the year) and thus VMR cannot be obtained reliably during the day (Savijärvi et al. 2016; Martínez et al. 2016).

The large seasonal variability of the daily maximum RH shown in Fig. 14 (top) is mainly controlled by near-surface temperatures and not by atmospheric water content. The highest annual values of about $70 \%$ occur in early winter $\left(L_{\mathrm{s}}=93^{\circ}\right)$, coinciding with the minimum annual near-surface air and ground temperatures (Fig. 5, top and Fig. 7), while the lowest annual (daily maximum) $\mathrm{RH}$ values of $\sim 10 \%$ occur around late spring and early summer, coinciding with the highest annual near-surface air and ground temperatures. Interestingly, the seasonal evolution of the daily maximum $\mathrm{RH}$ is anti-correlated with that of the nearsurface nighttime VMR shown in Fig. 14 (bottom). The lowest annual values of VMR occur in late fall and winter, when the daily maximum RH is the highest, while the highest annual values of VMR occur in late winter, spring and early summer, when the daily maximum RH is the lowest.

The sol-to-sol variability in VMR seems to be larger in spring and summer than in late fall and winter (Fig. 14, bottom). This variability may be related to the uncertainty in VMR estimations rather than to actual variations in VMR (Martínez et al. 2016). This occurs because the most accurate daily VMR values are obtained when the relative humidity is the highest. Therefore, VMR values obtained in spring and summer, when even the diurnal maximum RH is low, have greater uncertainties than VMR values obtained in late fall and winter, when the diurnal maximum RH is the highest. 
The detection of surface frost or near-surface fog is important because it allows the independent estimation of the water vapor content if the temperature is known. Nighttime frost was detected at the PHX site by the Robotic Arm Camera from sol 80 (early summer, $L_{\mathrm{s}}$ $=113^{\circ}$ ) until the end of the mission on sol 151 (late summer, $\left.L_{\mathrm{s}}=149^{\circ}\right)($ Smith et al. 2009), coinciding with a gradual decrease in atmospheric pressure and ground and nearsurface air temperatures (Fig. 3 top, Fig. 5 top, Fig. 8 bottom). Also during the second half of the PHX mission, the LIDAR instrument observed two regular daily patterns of water-ice cloud formation: a surface-based cloud (ice fog) forming near midnight, and a 4-km-high cloud layer forming around 01:00 LMST (Whiteway et al. 2009; Dickinson et al. 2010; Moores et al. 2011). Using values of temperature and atmospheric pressure near the surface at midnight, and at $4 \mathrm{~km}$ height at 01:00 LMST, the evolution of the VMR at the PHX site can be inferred. Near the surface, we obtain an estimate for the near-surface VMR that decreases from $\sim 210 \mathrm{ppm}$ on sol 80 to $\sim 15 \mathrm{ppm}$ on sol 150 . These values were obtained using MET midnight measurements of air temperature at $2 \mathrm{~m}$ above the surface and atmospheric pressure at the lander deck ( $200 \mathrm{~K}$ and $775 \mathrm{~Pa}$ on sol 80 and $185 \mathrm{~K}$ and $734 \mathrm{~Pa}$ on sol 150). At $4 \mathrm{~km}$ height, Dickinson et al. (2010) obtained an estimate for the VMR decreasing from $\sim 1300 \mathrm{ppm}\left(6.8 \mathrm{mg} / \mathrm{m}^{3}\right.$ at $-64.3{ }^{\circ} \mathrm{C}$ and $\left.\sim 500 \mathrm{~Pa}\right)$ on sol 99 to $\sim 575 \mathrm{ppm}\left(2.9 \mathrm{mg} / \mathrm{m}^{3}\right.$ at $-70.2{ }^{\circ} \mathrm{C}$ and $\sim 470 \mathrm{~Pa}$ ) on sol 150 (Dickinson et al. 2010). The lower values and larger relative decrease in VMR near the surface highlight the key role played by the deposition and sublimation of $\mathrm{H}_{2} \mathrm{O}$ onto and from the ground in the seasonal $\mathrm{H}_{2} \mathrm{O}$ cycle at the PHX site. Additionally, the decrease in VMR estimated at $4 \mathrm{~km}$ height is consistent with that in the column-integrated water abundance at PHX site measured by the Compact Reconnaissance Imaging Spectrometer for Mars (CRISM) instrument on the Mars Reconnaissance Orbiter (MRO) between sols 99 and 150 (Tamppari et al. 2010), indicating that the $\mathrm{H}_{2} \mathrm{O}$ seasonal cycle at the PHX site is mostly confined to the lowest $4 \mathrm{~km}$ of the atmosphere (Dickinson et al. 2010).

At the Viking Lander 2 site, a thin layer of frost was observed on the ground for about 250 sols, from late fall $\left(L_{\mathrm{s}}=230^{\circ}\right)$ until early spring $\left(L_{\mathrm{s}}=16^{\circ}\right)$ in the first year of the mission (Jones et al. 1979; Wall 1981). At this location, surface frost formed at night and persisted throughout the day. Since the VL missions did not carry a ground temperature sensor, an estimate for the water vapor VMR at the ground cannot be obtained. Furthermore, air temperatures measured at $1.6 \mathrm{~m}$ (Fig. 5, top) during this period, which ranged from about 160 to $190 \mathrm{~K}$ at night, cannot be used unambiguously to determine the near-surface water vapor VMR because near-surface fog was not detected. However, Ryan et al. (1982) estimated VMR values at both VL sites indirectly. By attributing an increase in the rate of nocturnal air temperature decrease to ice fog formation (thus representing the frost point temperature), they inferred values of the VMR between 01:00 and 03:00 LMST throughout the year at both sites. At the VL1, nocturnal VMR values ranged from $\sim 17 \mathrm{ppm}$ in late autumn $\left(L_{\mathrm{s}} \sim 250^{\circ}\right)$ to $\sim 200 \mathrm{ppm}$ in mid summer $\left(L_{\mathrm{s}} \sim 130^{\circ}\right)$, while at the VL2 VMR values ranged from $<1 \mathrm{ppm}$ in early winter $\left(L_{\mathrm{s}} \sim 280^{\circ}\right)$ to $\sim 200 \mathrm{ppm}$ in late spring $\left(L_{\mathrm{s}} \sim\right.$ $60^{\circ}$ ).

Ground frost has not been observed in situ at lower latitudes such as those of the VL1, MER, MPF and MSL missions landing sites. However, possible visual evidence for the formation of frost has been found on the deck and calibration target of the MER-B on sol 257 $\left(L_{\mathrm{s}} \sim 105^{\circ}\right)$ (Möhlmann 2008). Additionally, near-surface fog was imaged by the Mars Express High Resolution Stereo Camera in Valles Marineris ( $\left.\sim 10^{\circ} \mathrm{S}\right)$ (Möhlmann et al. 2009). At the MSL site, indirect evidence for frost formation on a few sols during late fall and early winter in MY 32 has been provided from the analysis of relative humidity and ground temperature measurements (Martínez et al. 2016), further supported by numerical modeling (Savijärvi et al. 2015; Steele et al. 2017). 


\section{Discussion}

In this section we briefly describe the meteorological stations being developed for future in-situ measurements on Mars, propose measurements to improve our understanding of the Martian dust and $\mathrm{H}_{2} \mathrm{O}$ cycles, and discuss the potential for liquid water formation under Mars' present day conditions and its implications for future Mars missions.

\subsection{Future Meteorological Stations}

In the next few years, in-situ meteorological measurements at the surface of Mars will continue with the Temperature and Wind Sensors (TWINS) instrument onboard NASA's 2018 InSight mission (Velasco and Rodríguez-Manfredi 2015), the Meteorological (METEO) and the Habitability, Brine, Irradiation and Temperature (HABIT) instruments onboard the ExoMars 2020 surface platform (ESA 2016), and the Mars Environmental Dynamics Analyzer (MEDA) instrument onboard NASA's Mars 2020 mission (Rodriguez-Manfredi et al. 2014). In addition to extending the current record of meteorological measurements to other locations on Mars, HABIT will measure changes in the hydration state (including potential formation of liquid brine) of hygroscopic salts exposed to Martian air to shed light on the water cycle, while MEDA will measure the surface energy balance (upward and downward long-wave and short-wave radiation fluxes) and dust particle morphology to characterize the energy exchange with the atmosphere and the radiative properties of dust particles.

\subsection{Improving Our Understanding of the Dust and $\mathrm{H}_{2} \mathrm{O}$ Cycles}

The characterization of dust-lifting processes is important to improve our knowledge of the Martian dust cycle and the various feedback processes associated with it. The Dust Characterization, Risk Assessment and Environment Analyzer on the Martian Surface (DREAMS) instrument onboard the ExoMars 2016 surface lander (Bettanini et al. 2014) was designed to shed light on dust-lifting processes, but it was unfortunately lost during descent. Windblown sand, or 'saltation,' causes wind erosion and ejects dust aerosols into the Martian atmosphere through impact of saltating particles on the ground (Greeley and Iversen 1985; Almeida et al. 2008). Electrification of wind-blown sand, dust devils and dust storms could produce electric discharges (Eden and Vonnegut 1973) and reduce the wind stress required to lift particles from the surface of Mars (Kok and Renno 2006). In addition, dust lifting might have important implications for habitability because, along with the transport of minerals by the wind, aeolian processes provide a means for the exchange of nutrients and energy sources between the atmosphere and the shallow subsurface (Farrell et al. 2004). The growth of segregated ice and salt crystals in rock pores is a critical weathering process on Earth, and there is evidence that this process is currently active on Mars (Hallet 2006). To improve our understanding of dust-lifting processes, we propose measurements of the particle mass flux, the near surface electric field, and the depth of the saltation layer at heights ranging from 0.01 to $2 \mathrm{~m}$ above the ground (Kok and Renno 2009a, 2009b; Esposito et al. 2016), in combination with measurements of the near surface wind speed, the wind shear, and the soil particle size distribution and particle cohesion (Kok and Renno 2006).

Determining the relative importance of the exchange of physically adsorbed water between the regolith and the atmosphere at different time scales is important to improve our understanding of the current $\mathrm{H}_{2} \mathrm{O}$ cycle. Although there is consensus that adsorbed water exchanges seasonally between the regolith and the atmosphere, the significance of such an exchange at diurnal time-scales remains unclear (Zent et al. 1993; Titov et al. 1995; 
Zent et al. 2001). In particular, it is not known whether kinetics would allow for the exchange of adsorbed water on the hourly time scales necessary for tracking diurnal insolation (Titov et al. 1995; Zent et al. 2001). Unfortunately, ground-based estimations of near-surface water VMR with full diurnal coverage are not available (Sect. 3.6). Processed PHX/TECP atmospheric RH values are not available in the NASA PDS (Sect. 2.4), while MSL/REMSderived daytime VMR values present large uncertainties and cannot be used to address the diurnal cycle (Savijärvi et al. 2015; Martínez et al. 2016). However, the strong correlation between REMS-derived nighttime VMR values and surface and near-surface temperature values at Gale crater can be used to shed some light on the exchange of water between the regolith and the atmosphere.

The lowest annual values of VMR (Fig. 14, bottom) coincide with the lowest annual values of surface and near-surface air temperature (Fig. 5, top and Fig. 7), suggesting that the regolith plays a significant role in exchanging water vapor with the atmosphere at Gale crater. Two processes could account for such an exchange: adsorption/desorption of water vapor and deposition/sublimation of frost. Adsorption by the regolith is expected to be more intense at lower temperatures, favoring this mechanism as a driver for the exchange of water vapor between the regolith and the atmosphere at Gale. In addition, Savijärvi et al. (2016) show that diurnal cycles of RH measured at Gale can be more accurately simulated when a temperature dependent soil adsorption scheme is used. Potential nighttime frost formation in late fall and early winter (Martínez et al. 2016; Steele et al. 2017) might also explain the annual lowest values of near-surface nighttime VMR at this time of the year (Fig. 14, bottom), although as of February 2017 frost has not been detected by the MSL Curiosity rover.

While the strong correlation between VMR and temperature is consistent with atmosphere-regolith interactions, large-scale seasonal circulation patterns have the potential to create seasonal differences in the near-surface VMR values. Rafkin et al. (2016) show that the air mass in Gale mixes well with external air during southern summer $\left(L_{\mathrm{s}} \sim 270^{\circ}\right)$, coinciding with relatively high values of near-surface VMR (Fig. 14, bottom). On the contrary, the mixing between the air in and external to Gale is more limited in other seasons, and in particular during southern winter $\left(L_{\mathrm{s}} \sim 90^{\circ}\right)$ when the near-surface VMR shows the lowest annual values. However, air entering Gale crater during southern summer (when the North Pole is a water trap) has a northerly component (Rafkin et al. 2016), and thus the air advected into Gale is not expected to be particularly moist. Therefore, soil-atmosphere interactions seem to play a prevalent role in exchanging water vapor at Gale.

To improve our understanding of the exchange of water between the regolith and the atmosphere, we propose measurements of near-surface water vapor content throughout the diurnal cycle. Such measurements could be made either by a relative humidity sensor with accuracy better than $1 \%$ during the daytime (so that daytime derived-VMR are reliable given typical daytime values of RH and air temperatures at Gale crater), or by a sensor capable of measuring VMR directly. Additionally, we propose simultaneous measurements of the vertical component of the wind speed at high frequency $(>1 \mathrm{~Hz})$ to calculate vertical turbulent transport of water vapor. Currently planned missions will not directly address dust lifting processes and the exchange of water vapor between the atmosphere and the regolith. Thus, we propose that missions past 2020 study these processes.

\subsection{Liquid Water and the $\mathrm{H}_{2} \mathrm{O}$ Cycle}

Liquid water at the surface and in the shallow subsurface of Mars is not required to account for current seasonal variations in the integrated $\mathrm{H}_{2} \mathrm{O}$ column abundance observed from orbit 
(Jakosky 1985; Richardson and Wilson 2002), which, in combination with modeling, have been used to determine the relative importance of the various processes controlling the seasonal $\mathrm{H}_{2} \mathrm{O}$ cycle. However, the potential presence of liquid water has important implications for the current habitability of Mars.

Mars has large reservoirs of water as ice and vapor, but pure liquid water is unlikely to be present, even temporarily, on the surface of Mars because it would quickly evaporate in the regions where it neither freezes nor boils (Ingersoll 1970; Haberle et al. 2001; Martínez and Renno 2013). However, the presence of water ice in the shallow subsurface midlatitude and polar regions (Boynton et al. 2002; Mitrofanov et al. 2002; Feldman et al. 2002; Byrne et al. 2009), along with the detection of perchlorates in polar and equatorial soil (Hecht et al. 2009; Glavin et al. 2013; Ming et al. 2014) and of chloride-bearing deposits in the southern highlands at low and midlatitudes (Osterloo et al. 2008), is important because they can melt this ice at Mars' present-day environmental conditions and produce liquid saline water (brine) (Clark 1978; Brass 1980; Clark and Van Hart 1981; Haberle et al. 2001; Chevrier and Altheide 2008; Rennó et al. 2009; McEwen et al. 2011; Ojha et al. 2015).

Two mechanisms have been suggested for brine formation on Mars: its formation by salts absorbing atmospheric water vapor (deliquescence) when the relative humidity exceeds a threshold value known as the deliquescence relative humidity and the temperature is above the salts' eutectic value (Clark 1978; Rennó et al. 2009; Davila et al. 2010; Gough et al. 2011; Nuding et al. 2015; Martín-Torres et al. 2015; Nikolakakos and Whiteway 2015), and its formation by salts melting water ice when the temperature exceeds the eutectic value of salts in contact with water ice (Brass 1980; Clark and Van Hart 1981; Fairén et al. 2009; Fischer et al. 2014). Perchlorate salts, in particular $\mathrm{Ca}\left(\mathrm{ClO}_{4}\right)_{2}, \mathrm{Mg}\left(\mathrm{ClO}_{4}\right)_{2}$ and $\mathrm{Na}\left(\mathrm{ClO}_{4}\right)$ salts, are extremely relevant for brine formation via deliquescence and melting because they have low eutectic temperatures and were found in polar and equatorial regions (Hecht et al. 2009; Glavin et al. 2013), suggesting that they are distributed globally.

The necessary conditions for both mechanisms to occur are more likely to be met in the Martian polar regions than at low and equatorial latitudes. In the polar regions, brine formation by the melting of ice in contact with salts is plausible because frost or snow are seasonally deposited on saline soils (Whiteway et al. 2009; Martínez et al. 2012), water ice is seasonally present in the shallow subsurface (Paige 1992; Mellon and Jakosky 1993; Schorghofer and Aharonson 2005; Cull et al. 2010), and temperatures exceed the eutectic value of salts detected on Mars during a significant fraction of the sol (from minutes to hours depending on the location and time of the year) (Möhlmann 2011; Fischer et al. 2014; Nuding et al. 2014; Fischer et al. 2016). Moreover, numerical modeling and laboratory experiments indicate that brine formation by deliquescence in the polar region is theoretically possible because simulated diurnal cycles of $\mathrm{RH}$ and temperature at the ground at the $\mathrm{PHX}$ site are compatible with deliquescence of $\mathrm{Ca}\left(\mathrm{ClO}_{4}\right)_{2}$ and $\mathrm{Mg}\left(\mathrm{ClO}_{4}\right)_{2}$ salts (Möhlmann 2011; Nuding et al. 2014; Nikolakakos and Whiteway 2015). However, other laboratory experiments indicate that deliquescence of perchlorates at the PHX site is not rapid enough to occur during the short periods of the day during which the environmental conditions are favorable for deliquescence because the kinetics of this reaction is too slow at Mars relevant values of temperature and water vapor pressure (Fischer et al. 2014).

At equatorial and low latitudes, brine formation by the melting of ice is unlikely because water ice is not thermodynamically stable in the shallow subsurface at these latitudes (Mellon and Jakosky 1993; Mellon et al. 2004; Schorghofer and Aharonson 2005). Similarly, brine formation by deliquescence is less likely to occur in these regions than at higher latitudes. Analyses of simultaneous measurements of the highest confidence possible of RH and ground temperature at Gale crater (Fig. 15, gray points) indicate that the environmental 


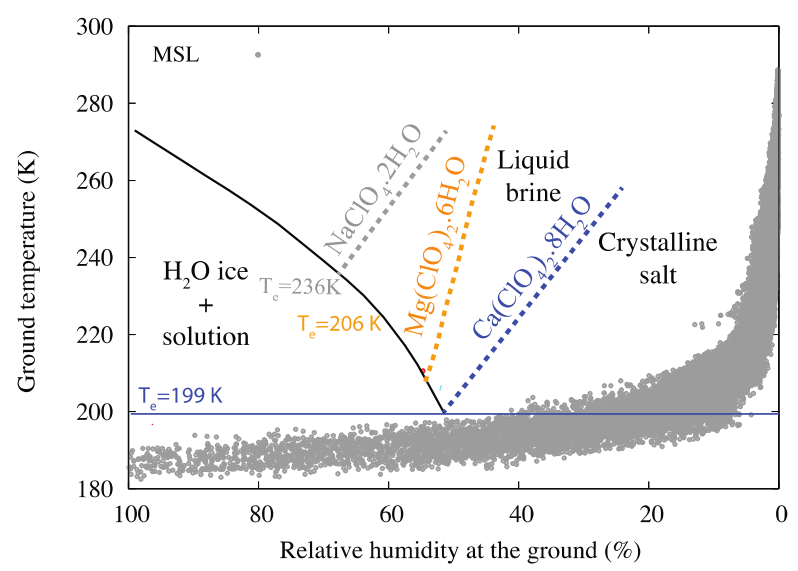

Fig. 15 Stability diagram of $\mathrm{Ca}\left(\mathrm{ClO}_{4}\right)_{2}, \mathrm{Mg}\left(\mathrm{ClO}_{4}\right)_{2}$ and $\mathrm{NaClO}_{4}$ salts, with superimposed values of relative humidity and temperature at the ground colored in gray for the first 1526 sols of the MSL mission. The environmental conditions at the MSL landing site are unlikely to lead to brine formation of perchlorate salts via deliquescence because they are too dry and cold. For each salt, the colored thick-dashed line represents the deliquescence relative humidity at which the various salts form aqueous solutions. The horizontal blue line represents the eutectic temperature of $\mathrm{Ca}\left(\mathrm{ClO}_{4}\right)_{2}$. The eutectic temperatures of $\mathrm{Mg}\left(\mathrm{ClO}_{4}\right)_{2}$ and $\mathrm{NaClO}_{4}$ are also shown in orange and gray colors. For simplicity, transitions between different hydrations states are not shown. Note that the relative humidity at the ground has been calculated as $\left[R H_{1.6 \mathrm{~m}} \times e_{S}\left(T_{1.6} \mathrm{~m}\right)\right] / e_{S}\left(T_{g}\right)$, where $R H_{1.6 \mathrm{~m}}$ and $T_{1.6 \mathrm{~m}}$ are the relative humidity and air temperature at $1.6 \mathrm{~m}$ measured by REMS and $e_{s}$ is the saturation vapor pressure over ice. Therefore, the water vapor pressure has been assumed constant in the first $1.6 \mathrm{~m}$

conditions are unlikely to lead to brine formation of perchlorates by deliquescence. MartínTorres et al. (2015) showed that the relative humidity and ground temperature at Gale crater are compatible with deliquescence of $\mathrm{Ca}\left(\mathrm{ClO}_{4}\right)_{2}$ salt. However, $\mathrm{RH}$ values used in that study were higher than those obtained using the most accurate REMS RH sensor recalibration performed in August 2016. Also, the theoretical value for the eutectic temperature of $\mathrm{Ca}\left(\mathrm{ClO}_{4}\right)_{2}$ of $194.5 \mathrm{~K}$ assumed by Martín-Torres et al. (2015) is lower than $\sim 199 \mathrm{~K}$, the value obtained experimentally in recent laboratory experiments (Marion et al. 2010; Fischer et al. 2016).

Testing hypotheses for brine formation on Mars is important to support future missions focusing on habitability and the search for life. Moreover, human exploration of Mars is expected to occur in the next few decades and in preparation for it, it is important to understand the resources available for sustaining humans on Mars. Therefore, a future mission to the polar regions could have a greater potential than a mission to equatorial and low latitudes to shed light on liquid water formation under present-day Martian environmental conditions.

A variety of instruments have been suggested to investigate brine formation on Mars. A Raman spectrometer can be used to clearly differentiate between ice and liquid brine (Fischer et al. 2016). One such instrument, the Raman Laser Spectrometer (RLS) will fly on the 2020 ExoMars Rover (Hutchinson et al. 2014) and another one in the same year in SHERLOC on Mars 2020 (Beegle et al. 2015). Although their main goal is to look for geological biosignatures, both have the capability to detect liquid brine. Brine on the Martian surface or in the shallow subsurface can also be detected by measuring soil conductivity (Heinz et al. 2016), microwave resonance frequencies (Zandonadi et al. 2015), or radar reflections. RIMFAX on the Mars 2020 rover (Hamran et al. 2015) and WISDOM on the 
ExoMars rover (Ciarletti et al. 2011) are future ground penetrating radars with the ability to investigate possible liquid water in the shallow Martian subsurface.

\section{Summary and Conclusions}

We have analyzed the complete set of in-situ meteorological data obtained from the Viking landers in the 1970s to today's Curiosity rover. We have processed these data to provide values of the highest confidence possible of atmospheric opacity, atmospheric pressure, nearsurface air temperature, ground temperature, near-surface wind speed and direction, and near-surface air relative humidity and water vapor content. Then we have studied the diurnal, seasonal and interannual variability of these quantities over a span of more than twenty Martian years to review our understanding of the modern near-surface climate of Mars.

The seasonal and latitudinal variation of solar insolation caused by the Martian obliquity and the large eccentricity of Mars' orbit drives the dust, $\mathrm{CO}_{2}$ and $\mathrm{H}_{2} \mathrm{O}$ cycles, which, coupled to radiative and dynamic processes, regulate the modern climate of Mars. Dust is ubiquitous in the Martian atmosphere and interacts strongly with solar and thermal radiation, affecting weather and climate and playing a major role in regional and global circulations. In contrast to Earth, the spatial and temporal variability of the dust content of the Martian atmosphere is extremely large, and this effect is enhanced by the low mass of the Martian atmosphere. During the aphelion season, dust opacity values are low and the intraseasonal and interannual variability is small at each landing site (Fig. 2, left column). In contrast, during the perihelion season the opacity values and the intraseasonal and interannual variability are larger (Fig. 2, left column), regardless of the hemispheric location. Repeatable regional dust storms during the perihelion season between $L_{\mathrm{s}}=210^{\circ}$ and $240^{\circ}$ and between $L_{\mathrm{s}}=320^{\circ}$ and $340^{\circ}$ produce seasonal increases in the atmospheric opacity at each landing site every year, while sporadic global dust storms between $L_{\mathrm{s}}=280^{\circ}$ and $300^{\circ}$ produce larger increases in atmospheric opacity every few years (Fig. 2, left column). During global dust storms, dust opacity values are extraordinarily high and the surface environmental conditions are significantly altered, with dramatic increases in the diurnal amplitude of the surface pressure (Fig. 3, bottom, MY 12) and dramatic decreases in the diurnal amplitude of the near-surface air temperature (Fig. 5, bottom, MY 12). However, values of the daily mean near-surface air temperature are not significantly changed because lower daytime temperatures are counterbalanced by greater nighttime temperatures (Fig. 5, top, MY 12).

The seasonal deposition of about $30 \%$ of the mass of the atmosphere in the polar caps during the cold seasons and its sublimation during the warm seasons strongly affects surface pressures (Fig. 3, top). At each landing site, the surface pressure shows an absolute annual maximum at $L_{\mathrm{s}} \sim 260^{\circ}$ (sublimation of the southern polar cap) and an absolute annual minimum at $L_{\mathrm{s}} \sim 150^{\circ}$ (deposition onto the southern polar cap). Additionally, the surface pressure presents a relative maximum at $L_{\mathrm{s}} \sim 55^{\circ}$ (sublimation of the northern polar cap) and a relative minimum at $L_{\mathrm{s}} \sim 345^{\circ}$ (deposition onto the northern polar cap). The larger sol-to-sol variability during the perihelion season than during the aphelion season at each landing site is caused by baroclinic instability in northern autumn and winter, which generates perturbations in surface pressure that peak at the latitude of the polar jet stream. Therefore, the largest sol-to-sol variations occur at the VL2 site (closest mission to the polar jet), followed by those at the VL1 (northern edge of the tropics) site, with the lowest variability in this sequence at the MSL site in the southern tropics. The diurnal amplitude of the surface pressure, also called the diurnal atmospheric tide, increases with increasing atmospheric aerosol content and proximity to the equator. Therefore, it shows larger values 
in the perihelion season than during the aphelion season at each landing site, with the largest values observed at the MSL site due to its proximity to the equator (Fig. 3, bottom).

The near-surface thermal environment at each landing site is primarily governed by the solar insolation reaching the surface. At each landing site, the maximum and minimum annual near-surface air and ground temperature (Fig. 5, top and Fig. 7) coincide with the annual maximum and minimum in surface solar insolation (Fig. 2). Following stronger seasonal variations in surface solar insolation at higher latitudes (Fig. 2), the annual amplitude in near-surface air temperature at each site increases with increasing latitude (Fig. 5, top). As for the surface pressure, larger sol-to-sol variations in the near-surface air temperature during the perihelion season are caused by baroclinic eddies in the northern hemisphere during autumn and winter. The diurnal amplitude of ground temperature at the MSL site (the only mission with full diurnal coverage) is primarily governed by the type of terrain, and in particular by its thermal inertia. Changes in atmospheric opacity can also regulate the diurnal amplitude of ground temperature, but their impact has been smaller than that produced by changes in thermal inertia, at least for the moderately low opacity values measured at Gale as of February 2017.

Of all the variables examined here, wind speed and direction are most strongly influenced by local and regional topography. This is particularly true for the MSL rover, where daytime upslope/nighttime downslope winds dominate the results shown (Figs. 10-12i). They are typically least affected by local variations in atmospheric opacity, although regional and global scale changes may greatly affect winds via their impact on the global circulation, thermal tides, and wave activity. For example, the altered circulation 1977b global dust storm produced faster wind speeds (Fig. 9), less sol-to-sol variability, and a complete change in the diurnal variation of wind speed and direction measured at the VL2 landing site, compared to the same time the following year (cf. Figs. 10-12c and 12g). This was due to the much stronger global circulation, suppression of baroclinic wave activity, and altered amplitudes of tidal components.

Only the PHX and MSL carried sensors to measure the near-surface relative humidity. At the MSL site, the daily maximum RH occurs between 04:00 and 06:00 LMST (Fig. 13) throughout the year, coinciding with the coldest time period of the day. Daytime values are extremely low, staying below $<5 \%$ between 10:00 and 18:00 LMST regardless of the season. The large seasonal variability of the daily maximum RH (Fig. 14, top) is controlled by near-surface temperatures. The highest annual values of about $70 \%$ occur in early winter $\left(L_{\mathrm{s}}=93^{\circ}\right)$, coinciding with the minimum annual near-surface air and ground temperatures (Fig. 5, top and Fig. 7). Similarly, the lowest annual (daily maximum) RH values of $\sim 10 \%$ occur around late spring and early summer, coinciding with the highest annual near-surface air and ground temperatures. At the PHX site, processed values of RH are not available in the NASA PDS, but LIDAR and SSI observations show that the ground and near-surface air were saturated at nighttime throughout the second half of the mission.

The near-surface water content has not been directly measured by any rover or lander, but it can be derived indirectly either from simultaneous measurements of $\mathrm{RH}$, temperature and pressure at the MSL site, or from the detection of surface frost or near-surface fog (provided that the temperature is known) at the PHX site. At the MSL site, daytime REMS-derived VMR values present large uncertainties due to extremely low RH, and only nighttime values can be derived reliably. The lowest annual values $(<5 \mathrm{ppm})$ occur in late fall and winter (Fig. 14 bottom), when the daily maximum RH is the highest (Fig. 14, top) and surface and near-surface air temperatures are the coldest (Fig. 5, top and Fig. 7), while the highest annual values of VMR occur in late winter, spring and early summer ( $\sim 70 \mathrm{ppm})$, when the daily maximum RH is the lowest and surface and near-surface air temperatures are the 
warmest. The strong correlation between nighttime values of VMR and temperature suggests that the regolith plays a significant role in exchanging water vapor with the regolith, with adsorption/desorption as the most likely mechanism. At the PHX site, the LIDAR instrument observed two regular daily patterns of water-ice cloud formation from sol 80 (early summer, $L_{\mathrm{s}}=113^{\circ}$ ) until the end of the mission on sol 151 (late summer, $L_{\mathrm{s}}=149^{\circ}$ ): a surfacebased cloud forming near midnight, and a 4-km-high cloud forming at about 01:00 LMST. Assuming saturated conditions at both heights and times between sols 80 and 150, nighttime VMR values decreasing from $\sim 210 \mathrm{ppm}$ to $\sim 15 \mathrm{ppm}$ near the surface, and from $\sim 1300 \mathrm{ppm}$ to $\sim 575 \mathrm{ppm}$ at $4 \mathrm{~km}$ high are obtained. The lower values and stronger decrease in VMR near the surface highlight the key role played by the deposition and sublimation of $\mathrm{H}_{2} \mathrm{O}$ onto and from the ground in the seasonal $\mathrm{H}_{2} \mathrm{O}$ cycle at the PHX site.

The characterization of dust-lifting processes and the exchange of adsorbed water between the regolith and the atmosphere at different time scales are important to improve our knowledge of the Martian dust and $\mathrm{H}_{2} \mathrm{O}$ cycles, but currently planned missions will not directly address these processes. We have proposed in Sect. 5 key measurements to study these processes and shed light on both cycles. Furthermore, we have shown that the necessary conditions for brine formation to occur, either by deliquescence or melting, are more likely to be met in the Martian polar regions than at low and equatorial latitudes. Therefore, a future mission to the polar regions could have a greater potential than a mission to equatorial and low latitudes to shed light on liquid water formation under present-day Martian environmental conditions.

Acknowledgements This research is supported by JPL grant number 1449038 and by the NASA Mars Data Analysis Program: Award \# NNX15AM53G. We thank the MSL and REMS Teams for supporting this investigation. We also want to thank the reviewers for their excellent suggestions to improve the paper. A.D.V.-R. wishes to acknowledge the Spanish Ministry of Economy and Competitiveness (MINECO) for FPI fellowship (BES-2012-059241). A.G.F. was supported by the Project "icyMARS", European Research Council Starting Grant No. 307496.

Open Access This article is distributed under the terms of the Creative Commons Attribution 4.0 International License (http://creativecommons.org/licenses/by/4.0/), which permits unrestricted use, distribution, and reproduction in any medium, provided you give appropriate credit to the original author(s) and the source, provide a link to the Creative Commons license, and indicate if changes were made.

\section{References}

M.P. Almeida, E.J. Parteli, J.S. Andrade, H.J. Herrmann, Giant saltation on Mars. Proc. Natl. Acad. Sci. USA 105(17), 6222-6226 (2008)

D. Banfield, B.J. Conrath, M.D. Smith, P.R. Christensen, R.J. Wilson, Forced waves in the Martian atmosphere from MGS TES nadir data. Icarus 161(2), 319-345 (2003)

J.R. Barnes, Time spectral analysis of midlatitude disturbances in the Martian atmosphere. J. Atmos. Sci. 37(9), 2002-2015 (1980)

J.R. Barnes, Midlatitude disturbances in the Martian atmosphere: a second Mars year. J. Atmos. Sci. 38(2), 225-234 (1981)

J.R. Barnes, J.B. Pollack, R.M. Haberle, C.B. Leovy, R.W. Zurek, H. Lee, J. Schaeffer, Mars atmospheric dynamics as simulated by the NASA Ames general circulation model. 2. Transient baroclinic eddies. J. Geophys. Res., Planets 98(E2), 3125-3148 (1993)

S. Basu, M.I. Richardson, R.J. Wilson, Simulation of the Martian dust cycle with the GFDL Mars GCM. J. Geophys. Res. 109, E11006 (2004). doi:10.1029/2004JE002243

L. Beegle, R. Bhartia, M. White, L. DeFlores, W. Abbey, Y.H. Wu, B. Cameron, J. Moore, M. Fries, A. Burton, K.S. Edgett, SHERLOC: scanning habitable environments with Raman \& luminescence for organics \& chemicals, in IEEE Aerospace Conference (2015), pp. 1-11 
C. Bettanini, F. Esposito, S. Debei, C. Molfese, I.A. Rodríguez, G. Colombatti, A.-M. Harri, F. Montmessin, C. Wilson, A. Aboudan, S. Abbaki, The DREAMS experiment on the ExoMars 2016 mission for the study of Martian environment during the dust storm season, in 2014 IEEE Metrology for Aerospace, MetroAeroSpace (2014), pp. 167-173

S.L. Blumsack, P.J. Gierasch, W.R. Wessel, An analytical and numerical study of the Martian planetary boundary layer over slopes. J. Atmos. Sci. 30(1), 66-82 (1973)

W.V. Boynton, W.C. Feldman, S.W. Squyres, T.H. Prettyman, J. Brückner, L.G. Evans, R.C. Reedy, R. Starr, J.R. Arnold, D.M. Drake, P.A.J. Englert, Distribution of hydrogen in the near surface of Mars: evidence for subsurface ice deposits. Science 297(5578), 81-85 (2002)

H.M. Böttger, S.R. Lewis, P.L. Read, F. Forget, The effects of the martian regolith on GCM water cycle simulations. Icarus 177(1), 174-189 (2005)

G.W. Brass, Stability of brines on Mars. Icarus 42, 20-28 (1980). doi:10.1016/0019-1035(80)90237-7

A.F. Bridger, J.R. Murphy, Mars' surface pressure tides and their behavior during global dust storms. J. Geophys. Res. 103(E4), 8587-8601 (1998)

S. Byrne, C.M. Dundas, M.R. Kennedy, M.T. Mellon, A.S. McEwen, S.C. Cull, I.J. Daubar, D.E. Shean, K.D. Seelos, S.L. Murchie, B.A. Cantor, Distribution of mid-latitude ground ice on Mars from new impact craters. Science 325(5948), 1674-1676 (2009)

B.A. Cantor, P.B. James, M. Caplinger, M.J. Wolff, Martian dust storms: 1999 Mars Orbiter Camera observations. J. Geophys. Res. 106, 23,653-23,687 (2001)

T.E. Chamberlain, H.L. Cole, R.G. Dutton, G.C. Greene, J.E. Tillman, Atmospheric measurements on Mars: the Viking Meteorology Experiment. Bull. Am. Meteorol. Soc. 57(9), 1094-1104 (1976)

V.F. Chevrier, T.S. Altheide, Low temperature aqueous ferric sulfate solutions on the surface of Mars. Geophys. Res. Lett. 35, L22101 (2008). doi:10.1029/2008GL035489

V. Ciarletti, C. Corbel, D. Plettemeier, P. Cais, S.M. Clifford, S.E. Hamran, WISDOM GPR designed for shallow and high-resolution sounding of the Martian subsurface. Proc. IEEE 99(5), 824-836 (2011)

B.C. Clark, Implications of abundant hygroscopic minerals in the Martian regolith. Icarus 34, 645-665 (1978). doi:10.1016/0019-1035(78)90052-0

B.C. Clark, D.C. Van Hart, The salts of Mars. Icarus 45(2), 370-378 (1981)

D.S. Colburn, J.B. Pollack, R.M. Haberle, Diurnal variations in optical depth at Mars. Icarus 79(1), 159-189 (1989). doi:10.1016/0019-1035(89)90114-0

B. Conrath, R. Curran, R. Hanel, V. Kunde, W. Maguire, J. Pearl, J. Pirraglia, J. Walker, Atmospheric and surface properties of Mars obtained by infrared spectroscopy on Mariner 9. J. Geophys. Res. 78, 42674278 (1973)

S.C. Cull, R.E. Arvidson, R.V. Morris, M. Wolff, M.T. Mellon, M.T. Lemmon, Seasonal ice cycle at the Mars Phoenix landing site. 2. Postlanding CRISM and ground observations. J. Geophys. Res.: Planets 115(E5), E00E19 (2010)

F. Daerden, J.A. Whiteway, R. Davy, C. Verhoeven, L. Komguem, C. Dickinson, P.A. Taylor, N. Larsen, Simulating observed boundary layer clouds on Mars. Geophys. Res. Lett. 37(4), L04203 (2010)

A.F. Davila, L. Gago Duport, R. Melchiorri, J. Jaenchen, S. Valea, A. de los Rios, A.G. Fairén, D. Möhlmann, C. McKay, J. Wierzchos, Hygroscopic salts and the potential for life on Mars. Astrobiology 10, 617-628 (2010)

R. Davy, J.A. Davis, P.A. Taylor, C.F. Lange, W. Weng, J. Whiteway, H.P. Gunnlaugson, Initial analysis of air temperature and related data from the Phoenix MET station and their use in estimating turbulent heat fluxes. J. Geophys. Res. 115, E00E13 (2010). doi:10.1029/2009JE003444

M. de la Torre-Juárez, D.M. Kass, R.M. Haberle, J. Gómez-Elvira, A.M. Harri, A. Kleinboehl, H. Kahanpää, M.A. Kahre, M.T. Lemmon, J. Martín-Torres, C.E. Newman, Pressure oscillations on the surface of Gale Crater and coincident observations of global circulation patterns, in AGU Fall Meeting Abstracts, vol. 1 (2014), p. 3939

M. de la Torre-Juárez, J. Gomez-Elvira, S.D. Guzewich, M.T. Lemmon, G.M. Martinez, E. Mason, S. Navarro, C.E. Newman, M.D. Smith, A. de Vicente-Retortillo, Influence of the atmospheric opacity cycle on the near surface environment of Gale Crater on Mars, in AAS/Division for Planetary Sciences Meeting Abstracts, vol. 48 (2016)

C. Dickinson, J.A. Whiteway, L. Komguem, J.E. Moores, M.T. Lemmon, LIDAR measurements of clouds in the planetary boundary layer on Mars. Geophys. Res. Lett. 37(18), L18203 (2010)

H. Eden, B. Vonnegut, Electrical breakdown caused by dust motion in low-pressure atmospheresconsiderations for Mars. Science 180(4089), 962-963 (1973)

M.D. Ellehoj, H.P. Gunnlaugsson, P.A. Taylor, H. Kahanpää, K.M. Bean, B.A. Cantor, B.T. Gheynani, L. Drube, D. Fisher, A.M. Harri, C. Holstein-Rathlou, Convective vortices and dust devils at the Phoenix Mars mission landing site. J. Geophys. Res., Planets 115(E4), E00E16 (2010)

ESA (2016), ExoMars 2020 surface platform. Available online at http://exploration.esa.int/mars/56933exomars-2018-surface-platform 
F. Esposito, R. Molinaro, C.I. Popa, C. Molfese, F. Cozzolino, L. Marty, K. Taj-Eddine, G. Di Achille, G. Franzese, S. Silvestro, G.G. Ori, The role of the atmospheric electric field in the dust-lifting process. J. Geophys. Res. 43(10), 5501-5508 (2016)

A.G. Fairén, A.F. Davila, L.G. Duport, R. Amils, C. McKay, Stability against freezing of aqueous solutions on early Mars. Nature 459, 401-404 (2009)

W.M. Farrell, P.H. Smith, G.T. Delory, G.B. Hillard, J.R. Marshall, D. Catling, M. Hecht, D.M. Tratt, N. Renno, M.D. Desch, S.A. Cummer, J.G. Houser, B. Johnson, Electric and magnetic signatures of dust devils from 2000-2001 MATADOR desert tests. J. Geophys. Res. 109 (2004). doi:10.1029/ 2003JE002088

A. Fedorova, O. Korablev, J.-L. Bertaux, A. Rodin, A. Kiselev, S. Perrier, Mars water vapor abundance from SPICAM IR spectrometer: seasonal and geographic distributions. J. Geophys. Res., Planets 111(E9), E09S08 (2006)

W.C. Feldman, W.V. Boynton, R.L. Tokar, T.H. Prettyman, O. Gasnault, S.W. Squyres, R.C. Elphic, D.J. Lawrence, S.L. Lawson, S. Maurice, G.W. McKinney, Global distribution of neutrons from Mars: results from Mars Odyssey. Science 297(5578), 75-78 (2002)

E. Fischer, G.M. Martínez, H.M. Elliott, N.O. Rennó, Experimental evidence for the formation of liquid saline water on Mars. Geophys. Res. Lett. 41, 4456-4462 (2014). doi:10.1002/2014GL060302

E. Fischer, G.M. Martínez, N.O. Renno, Formation and persistence of brine on Mars: experimental simulations throughout the diurnal cycle at the Phoenix landing site. Astrobiology 16(12), 937-948 (2016)

F.M. Flasar, R.M. Goody, Diurnal behavior of water on Mars. Planet. Space. Sci. 24, 161-181 (1976)

F. Forget, F. Hourdin, R. Fournier, C. Hourdin, O. Talagrand, M. Collins, S.R. Lewis, P.L. Read, J.-P. Huot, Improved general circulation models of the Martian atmosphere from the surface to above $80 \mathrm{~km}$. J. Geophys. Res. 104, 24,155-24,176 (1999)

T. Fouchet, E. Lellouch, N.I. Ignatiev, F. Forget, D.V. Titov, M. Tschimmel, F. Montmessin, V. Formisano, M. Giuranna, A. Maturilli, T. Encrenaz, Martian water vapor: Mars Express PFS/LW observations. Icarus 190(1), 32-49 (2007)

P.J. Gierasch, R.M. Goody, The effect of dust on the temperature of the Martian atmosphere. J. Atmos. Sci. 29, 400-402 (1972)

D.P. Glavin, C. Freissinet, K.E. Miller, J.L. Eigenbrode, A.E. Brunner, A. Buch, B. Sutter, P.D. Archer, S.K. Atreya, W.B. Brinckerhoff, M. Cabane, Evidence for perchlorates and the origin of chlorinated hydrocarbons detected by SAM at the Rocknest aeolian deposit in Gale Crater. J. Geophys. Res., Planets 118(10), 1955-1973 (2013)

R.V. Gough, V.F. Chevrier, K.J. Baustian, M.E. Wise, M.A. Tolbert, Laboratory studies of perchlorate phase transitions: support for 391 metastable aqueous perchlorate solutions on Mars. Earth Planet. Sci. Lett. 312(392), 371-377 (2011)

J. Gómez-Elvira, C. Armiens, L. Castañer, M. Domínguez, M. Genzer, F. Gómez, R. Haberle, A.M. Harri, V. Jiménez, H. Kahanpää, L. Kowalski, REMS: the environmental sensor suite for the Mars Science Laboratory rover. Space Sci. Rev. 170(1-4), 583-640 (2012)

J. Gómez-Elvira, C. Armiens, I. Carrasco, M. Genzer, F. Gómez, R. Haberle, V.E. Hamilton, A.M. Harri, H. Kahanpää, O. Kemppinen, A. Lepinette, Curiosity's rover environmental monitoring station: overview of the first 100 sols. J. Geophys. Res., Planets 119(7), 1680-1688 (2014)

R. Greeley, J.D. Iversen, Wind as a Geological Process on Earth, Mars, Venus, and Titan (Cambridge Univ. Press, New York, 1985)

R. Greeley, D. Waller, N. Cabrol, G. Landis, M.T. Lemmon, L. Neakrase, M.P. Hoffer, S. Thompson, P. Whelley, Gusev crater, Mars: observations of three dust devil seasons. J. Geophys. Res. 115, E00F02 (2010). doi:10.1029/2010JE003608

H.P. Gunnlaugsson, C. Holstein-Rathlou, J.P. Merrison, S. Knak Jensen, C.F. Lange, S.E. Larsen, M.B. Madsen, P. Nørnberg, H. Bechtold, E. Hald, J.J. Iversen, P. Lange, F. Lykkegaard, F. Rander, M. Lemmon, N. Renno, P. Taylor, P. Smith, Telltale wind indicator for the Mars Phoenix lander. J. Geophys. Res. 113, E00A04 (2008). doi:10.1029/2007JE003008

S.D. Guzewich, A.D. Toigo, M.I. Richardson, C.E. Newman, E.R. Talaat, D.W. Waugh, T.H. McConnochie, The impact of a realistic vertical dust distribution on the simulation of the Martian General Circulation. J. Geophys. Res., Planets 118(5), 980-993 (2013)

S.D. Guzewich, C.E. Newman, M. de la Torre Juárez, R.J. Wilson, M. Lemmon, M.D. Smith, H. Kahanpää, A.M. Harri, Atmospheric tides in Gale Crater, Mars. Icarus 268, 37-49 (2016)

R.M. Haberle, B.M. Jakosky, Sublimation and transport of water from the north residual polar cap on Mars. J. Geophys. Res., Solid Earth 95(B2), 1423-1437 (1990)

R.H. Haberle, B.L. Conway, J.B. Pollack, Some effects of global dust storms on the atmospheric circulation of Mars. Icarus 50(2-3), 322-367 (1982)

R.M. Haberle, J.B. Pollack, J.R. Barnes, R.W. Zurek, C.B. Leovy, J.R. Murphy, J. Schaeffer, Mars atmospheric dynamics as simulated by the NASA Ames General Circulation Model. I. The zonal-mean circulation. J. Geophys. Res. 98, 3093-3123 (1993a) 
R.M. Haberle, H.C. Houben, R. Hertenstein, T. Herdtle, A boundary layer for Mars: comparison with Viking lander and entry data. J. Atmos. Sci. 50, 1544-1559 (1993b)

R.M. Haberle, M.M. Joshi, J.R. Murphy, J.R. Barnes, J.T. Schofield, G. Wilson, M. Lopez-Valverde, J.L. Hollingsworth, A.F.C. Bridger, J. Schaeffer, General circulation model simulations of the Mars Pathfinder atmospheric structure investigation/meteorology data. J. Geophys. Res. 104, 8957-8974 (1999)

R.M. Haberle, C.P. McKay, J. Schaeffer, A.P. Zent, N.L. Cabrol, E.A. Grin, R. Quinn, On the possibility of liquid water on present-day Mars. J. Geophys. Res. 106(23), 317-323 (2001)

R.M. Haberle, J. Gómez-Elvira, M. de la Torre Juárez, A.M. Harri, J.L. Hollingsworth, H. Kahanpää, M.A. Kahre, M. Lemmon, F.J. Martín-Torres, M. Mischna, J.E. Moores, Preliminary interpretation of the REMS pressure data from the first 100 sols of the MSL mission. J. Geophys. Res., Planets 119(3), 440-453 (2014)

R.M. Haberle, M.A. Kahre, M. de la Torre-Juárez, D.M. Kass, Detection of northern hemisphere transient baroclinic eddies in REMS pressure data at Gale Crater Mars, in AAS/Division for Planetary Sciences Meeting Abstracts, vol. 48 (2016)

B. Hallet, Why do freezing rocks break? Science 314(5802), 1092-1093 (2006)

V.E. Hamilton, A.R. Vasavada, E. Sebastián, M. Torre-Juárez, M. Ramos, C. Armiens, R.E. Arvidson, I. Carrasco, P.R. Christensen, M.A. De Pablo, W. Goetz, Observations and preliminary science results from the first 100 sols of MSL Rover Environmental Monitoring Station ground temperature sensor measurements at Gale Crater. J. Geophys. Res., Planets 119(4), 745-770 (2014)

S.E. Hamran, T. Berger, S. Brovoll, L. Damsgård, Ø. Helleren, H.E. Amundsen, L. Carter, R. Ghent, J. Kohler, M. Mellon, D. Paige, RIMFAX: a GPR for the Mars 2020 rover mission, in IEEE 8th International Workshop on Advanced Ground Penetrating Radar, IWAGPR (2015), pp. 1-4

A.M. Harri, M. Genzer, O. Kemppinen, J. Gomez-Elvira, R.M. Haberle, J. Polkko, H. Savijärvi, N. Rennó, J.A. Rodriguez-Manfredi, W. Schmidt, M. Richardson, Mars Science Laboratory relative humidity observations: initial results. J. Geophys. Res., Planets 119(9), 2132-2147 (2014)

A.M. Harri, M. Genzer, O. Kemppinen, J. Gómez-Elvira, H. Savijärvi, T. McConnochie, M. De la Torre, R. Haberle, J. Polkko, M. Paton, M.I. Richardson, C.E. Newman, T. Siili, T. Makinen, Water cycle at Gale crater through MSL/REMS observations, in AAS/Division for Planetary Sciences Meeting Abstracts, vol. 48 (2016)

M.H. Hecht, J. Marshall, W.T. Pike, U. Staufer, D. Blaney, D. Braendlin, S. Gautsch, W. Goetz, H.R. Hidber, H.U. Keller, W.J. Markiewicz, Microscopy capabilities of the microscopy, electrochemistry, and conductivity analyzer. J. Geophys. Res., Planets 113(E3) (2008)

M.H. Hecht, S.P. Kounaves, R.C. Quinn, S.J. West, S.M.M. Young, D.W. Ming, D.C. Catling, B.C. Clark, W.V. Boynton, J. Hoffman, L.P. DeFlores, Detection of perchlorate and the soluble chemistry of Martian soil at the Phoenix lander site. Science 325(5936), 64-67 (2009)

J. Heinz, D. Schulze-Makuch, S.P. Kounaves, Deliquescence-induced wetting and RSL-like darkening of a Mars analogue soil containing various perchlorate and chloride salts. Geophys. Res. Lett. 43(10), 48804884 (2016)

S.L. Hess, R.M. Henry, C.B. Leovy, J.A. Ryan, J.E. Tillman, Meteorological results from the surface of Mars: Viking 1 and 2. J. Geophys. Res. 82(28), 4559-4574 (1977)

S.L. Hess, J.A. Ryan, J.E. Tillman, R.M. Henry, C.B. Leovy, The annual cycle of pressure on Mars measured by Viking landers 1 and 2. Geophys. Res. Lett. 7(3), 197-200 (1980)

D.P. Hinson, R.J. Wilson, M.D. Smith, B.J. Conrath, Stationary planetary waves in the atmosphere of Mars during southern winter. J. Geophys. Res., Planets 108(E1), 5004 (2003)

J.L. Hollingsworth, J.R. Barnes, Forced stationary waves in Mars winter atmosphere. J. Atmos. Sci. 53(3), 428-447 (1996)

C. Holstein-Rathlou, H.P. Gunnlaugsson, J.P. Merrison, K.M. Bean, B.A. Cantor, J.A. Davis, R. Davy, N.B. Drake, M.D. Ellehoj, W. Goetz, S.F. Hviid, C.F. Lange, S.E. Larsen, M.T. Lemmon, M.B. Madsen, M. Malin, J.E. Moores, P. Nørnberg, P. Smith, L.K. Tamppari, P.A. Taylor, Winds at the Phoenix landing site. J. Geophys. Res. 115, E00E18 (2010). doi:10.1029/2009JE003411

H. Houben, R.M. Haberle, R.E. Young, A.P. Zent, Modeling the Martian seasonal water cycle. J. Geophys. Res., Planets 102(E4), 9069-9083 (1997)

F. Hourdin, P. Le Van, F. Forget, O. Talagrand, Meteorological variability and the annual surface pressure cycle on Mars. J. Atmos. Sci. 50(21), 3625-3640 (1993)

I.B. Hutchinson, R. Ingley, H.G.M. Edwards, L. Harris, M. McHugh, C. Malherbe, J. Parnell, Raman spectroscopy on Mars: identification of geological and bio-geological signatures in Martian analogues using miniaturized Raman spectrometers. Philos. Trans. R. Soc., Math. Phys. Eng. Sci. 372(2030), 20140204 (2014)

A.P. Ingersoll, Mars: occurrence of liquid water. Science 168(3934), 972-973 (1970)

B.M. Jakosky, The seasonal cycle of water on Mars. Space Sci. Rev. 41(1-2), 131-200 (1985) 
B.M. Jakosky, C.B. Farmer, The seasonal and global behavior of water vapor in the Mars atmosphere: complete global results of the Viking atmospheric water detector experiment. J. Geophys. Res., Solid Earth 87(B4), 2999-3019 (1982)

B.M. Jakosky, R.M. Haberle, The seasonal behavior of water on Mars, in Mars, ed. by H.H. Kieffer et al. (Univ. of Ariz. Press, Tucson, 1992), pp. 969-1016

K.L. Jones, R.E. Arvidson, E.A. Guinness, S.L. Bragg, S.D. Wall, C.E. Carlston, D.G. Pidek, One Mars year: Viking lander imaging observations. Science 204(4395), 799-806 (1979)

M.M. Joshi, S.R. Lewis, P.L. Read, D.C. Catling, Western boundary currents in the Martian atmosphere: numerical simulations and observational evidence. J. Geophys. Res. 100(E3), 5485-5500 (1995). doi:10.1029/94JE02716

H. Kahanpää, C. Newman, J. Moores, M.P. Zorzano, J. Martín-Torres, S. Navarro, A. Lepinette, B. Cantor, M.T. Lemmon, P. Valentín-Serrano, A. Ullán, Convective vortices and dust devils at the MSL landing site: annual variability. J. Geophys. Res., Planets 121(8), 1514-1549 (2016)

R.A. Kahn, T.Z. Martin, R.W. Zurek, S.W. Lee, The Martian dust cycle, in Mars, ed. by H.H. Kieffer et al. (Univ. of Ariz. Press, Tucson, 1992), pp. 1017-1053

M.A. Kahre, J.R. Murphy, R.M. Haberle, Modeling the Martian dust cycle and surface dust reservoirs with the NASA Ames general circulation model. J. Geophys. Res. 111, E06008 (2006). doi:10.1029/ 2005JE002588

J.F. Kok, N.O. Renno, Enhancement of the emission of mineral dust aerosols by electric forces. Geophys. Res. Lett. 33, L19S10 (2006). doi:10.1029/2006GL026284

J.F. Kok, N.O. Renno, Electrification of wind-blown sand on Mars and its implications for atmospheric chemistry. Geophys. Res. Lett. 36(5), L05202 (2009a)

J.F. Kok, N.O. Renno, A comprehensive numerical model of steady state saltation (COMSALT). J. Geophys. Res. 114, D17204 (2009b)

M.T. Lemmon, M.J. Wolff, J.F. Bell III., M.D. Smith, B.A. Cantor, P.H. Smith, Dust aerosol, clouds, and the atmospheric optical depth record over 5 Mars years of the Mars Exploration Rover mission. Icarus 251, 96-111 (2015). doi:10.1016/j.icarus.2014.03.029

S.R. Lewis, D.P. Mulholland, P.L. Read, L. Montabone, R.J. Wilson, M.D. Smith, The solsticial pause on Mars. 1. A planetary wave reanalysis. Icarus 264, 456-464 (2016)

A. Määttänen, H. Savijärvi, Sensitivity tests with a one-dimensional boundary-layer Mars model. Bound.Layer Meteorol. 113(3), 305-320 (2004)

J.-B. Madeleine, F. Forget, E. Millour, L. Montabone, M.J. Wolff, Revisiting the radiative impact of dust on Mars using the LMD Global Climate Model. J. Geophys. Res. 116, E11010 (2011). doi:10.1029/ 2011JE003855

J.B. Madeleine, F. Forget, E. Millour, T. Navarro, A. Spiga, The influence of radiatively active water ice clouds on the Martian climate. Geophys. Res. Lett. 39(23) (2012)

J.A. Magalhães, The Martian Hadley circulation: comparison of "viscous" model predictions to observations. Icarus 70(3), 442-468 (1987)

G.M. Marion, D.C. Catling, K.J. Zahnle, M.W. Claire, Modeling aqueous perchlorate chemistries with applications to Mars. Icarus 207(2), 675-685 (2010)

T.Z. Martin, Thermal infrared opacity of the Mars atmosphere. Icarus 66(1), 2-21 (1986)

T.Z. Martin, H.H. Kieffer, Thermal infrared properties of the Martian atmosphere. 2. The $15 \mu \mathrm{m}$ band measurements. J. Geophys. Res., Solid Earth 84(B6), 2843-2852 (1979)

F.J. Martín-Torres, M.P. Zorzano, P. Valentín-Serrano, A.M. Harri, M. Genzer, O. Kemppinen, E.G. RiveraValentín, I. Jun, J. Wray, M.B. Madsen, W. Goetz, Transient liquid water and water activity at Gale crater on Mars. Nat. Geosci. 8, 357-361 (2015)

G.M. Martínez, N.O. Renno, Water and brines on Mars: current evidence and implications for MSL. Space Sci. Rev. 175(1-4), 29-51 (2013)

G.M. Martínez, N.O. Renno, H.M. Elliott, The evolution of the albedo of dark spots observed on Mars polar region. Icarus 221, 816-830 (2012)

G.M. Martínez, N. Rennó, E. Fischer, C.S. Borlina, B. Hallet, M. de la Torre Juárez, A.R. Vasavada, M. Ramos, V. Hamilton, J. Gómez-Elvira, R.M. Haberle, Surface energy budget and thermal inertia at Gale Crater: calculations from ground-based measurements. J. Geophys. Res., Planets 119(8), 1822-1838 (2014)

G.M. Martínez, E. Fischer, N.O. Rennó, E. Sebastián, O. Kemppinen, N. Bridges, C.S. Borlina, P.Y. Meslin, M. Genzer, A.H. Harri, A. Vicente-Retortillo, Likely frost events at Gale crater: analysis from MSL/REMS measurements. Icarus 280, 93-102 (2016)

A.S. McEwen, L. Ojha, C.M. Dundas, S.S. Mattson, S. Byrne, J.J. Wray, S.C. Cull, S.L. Murchie, N. Thomas, V.C. Gulick, Seasonal flows on warm Martian slopes. Science 333(6043), 740-743 (2011)

R. Melchiorri, T. Encrenaz, T. Fouchet, P. Drossart, E. Lellouch, B. Gondet, J.-P. Bibring, Y. Langevin, B. Schmitt, D. Titov, N. Ignatiev, Water vapor mapping on Mars using OMEGA/Mars express. Planet. Space Sci. 55, 333-342 (2006) 
M.T. Mellon, B.M. Jakosky, Geographic variations in the thermal and diffusive stability of ground ice on Mars. J. Geophys. Res. 98(E2), 3345-3364 (1993)

M.T. Mellon, W.C. Feldman, T.H. Prettyman, The presence and stability of ground ice in the southern hemisphere of Mars. Icarus 169, 324-340 (2004). doi:10.1016/j.icarus.2003.10.022

Mars Exploration Program Analysis Group (MEPAG), Mars Science Goals, Objectives, Investigations, and Priorities: 2015 Version (2015). Available at http://mepag.nasa.gov/reports/MEPAG\%20Goals_ Document_2015_v18_FINAL.pdf

D.W. Ming, P.D. Archer, D.P. Glavin, J.L. Eigenbrode, H.B. Franz, B. Sutter, A.E. Brunner, J.C. Stern, C. Freissinet, A.C. McAdam, P.R. Mahaffy, Volatile and organic compositions of sedimentary rocks in Yellowknife Bay, Gale Crater, Mars. Science 343(6169), 1245267 (2014)

M.A. Mischna, M.I. Richardson, R.J. Wilson, D.J. McCleese, On the orbital forcing of Martian water and $\mathrm{CO}_{2}$ cycles: A general circulation model study with simplified volatile schemes. J. Geophys. Res., Planets 108(E6), E01005 (2003)

I. Mitrofanov, D. Anfimov, A. Kozyrev, M. Litvak, A. Sanin, V. Tret'yakov, A. Krylov, V. Shvetsov, W.V. Boynton, C. Shinohara, D. Hamara, Maps of subsurface hydrogen from the high energy neutron detector, Mars Odyssey. Science 297(5578), 78-81 (2002)

L. Montabone, F. Forget, E. Millour, R.J. Wilson, S.R. Lewis, D. Kass, A. Kleinboehl, M.T. Lemmon, M.D. Smith, M.J. Wolff, Eight-year climatology of dust optical depth on Mars. Icarus 251, 65-95 (2015). doi:10.1016/j.icarus.2014.12.034

F. Montmessin, F. Forget, P. Rannou, M. Cabane, R.M. Haberle, Origin and role of water ice clouds in the Martian water cycle as inferred from a general circulation model. J. Geophys. Res., Planets 109(E10), E10004 (2004)

J.E. Moores, L. Komguem, J.A. Whiteway, M.T. Lemmon, C. Dickinson, F. Daerden, Observations of nearsurface fog at the Phoenix Mars landing site. Geophys. Res. Lett. 38(4), L04203 (2011)

Y. Moudden, J.C. McConnell, A new model for multiscale modeling of the martian atmosphere, GM3. J. Geophys. Res. 110, E04001 (2005). doi:10.1029/2004JE002354

D.T. Möhlmann, The influence of van der Waals forces on the state of water in the shallow subsurface of Mars. Icarus 195(1), 131-139 (2008)

D.T.F. Möhlmann, Latitudinal distribution of temporary liquid cryobrines on Mars. Icarus 214(1), 236-239 (2011)

D.T. Möhlmann, M. Niemand, V. Formisano, H. Savijärvi, P. Wolkenberg, Fog phenomena on Mars. Planet. Space Sci. 57(14), 1987-1992 (2009)

J.R. Murphy, C.B. Leovy, J.E. Tillman, Observations of Martian surface winds at the Viking lander 1 site. J. Geophys. Res. 95(B9), 14555-14576 (1990)

C.E. Newman, S.R. Lewis, P.L. Read, F. Forget, Modeling the Martian dust cycle. 1. Representations of dust transport processes. J. Geophys. Res. 107(E12), 5123 (2002a). doi:10.1029/2002JE001910

C.E. Newman, S.R. Lewis, P.L. Read, F. Forget, Modeling the Martian dust cycle. 2. Multiannual radiatively active dust transport simulations. J. Geophys. Res. 107(E12), 5124 (2002b). doi:10.1029/2002JE001920

C.N. Newman, J. Gómez-Elvira, M. Marín, S. Navarro, J. Torres, M.I. Richardson, J.M. Battalio, S.D. Guzewich, R. Sullivan, M. de la Torre-Juárez, A.R. Vasavada, N.T. Bridges, Winds measured by the Rover Environmental Monitoring Station (REMS) during the Mars Science Laboratory (MSL) rover's Bagnold Dunes Campaign and comparison with numerical modeling using MarsWRF. Icarus (2017, in press). doi:10.1016/j.icarus.2016.12.016

G. Nikolakakos, J.A. Whiteway, Laboratory investigation of perchlorate deliquescence at the surface of Mars with a Raman scattering lidar. Geophys. Res. Lett. 42, 7899-7906 (2015). doi:10.1002/2015GL065434

D.L. Nuding, E.G. Rivera-Valentín, R.D. Davis, R.V. Gough, V.F. Chevrier, M.A. Tolbert, Deliquescence and efflorescence of calcium perchlorate: an investigation of stable aqueous solutions relevant to Mars. Icarus 243, 420-428 (2014)

D.L. Nuding, R.D. Davis, R.V. Gough, M.A. Tolbert, The aqueous stability of a Mars salt analog: instant Mars. J. Geophys. Res., Planets 120(3), 588-598 (2015)

L. Ojha et al., Spectral evidence for hydrated salts in recurring slope lineae on Mars. Nat. Geosci. 8(11), 829-832 (2015)

M.M. Osterloo, V.E. Hamilton, J.L. Bandfield, T.D. Glotch, A.M. Baldridge, P.R. Christensen, L.L. Tornabene, F.S. Anderson, Chloride-bearing materials in the southern highlands of Mars. Science 319(5870), 1651-1654 (2008)

D.A. Paige, The thermal stability of near-surface ground ice on Mars. Nature 356(6364), 43-45 (1992)

S.C. Rafkin, J. Pla-Garcia, M. Kahre, J. Gomez-Elvira, V.E. Hamilton, M. Marín, S. Navarro, J. Torres, A. Vasavada, The meteorology of Gale Crater as determined from Rover Environmental Monitoring Station observations and numerical modeling. Part II. Interpretation. Icarus 280, 114-138 (2016)

P.L. Read, S.R. Lewis, The Martian Climate Revisited: Atmosphere and Environment of a Desert Planet (Springer, Chichester, 2004) 
N.O. Rennó, B.J. Bos, D. Catling, B.C. Clark, L. Drube, D. Fisher, W. Goetz, S.F. Hviid, H.U. Keller, J.F. Kok, S.P. Kounaves, Possible physical and thermodynamical evidence for liquid water at the Phoenix landing site. J. Geophys. Res., Planets 114(E1), E00E03 (2009)

M.I. Richardson, R.J. Wilson, Investigation of the nature and stability of the Martian seasonal water cycle with a general circulation model. J. Geophys. Res., Planets 107(E5), 5031 (2002)

M.I. Richardson, N.G. Heavens, M.A. Mischna, C.E. Newman, R. Wilson, M. Team, Why the diurnal pressure variation at curiosity is so large, in AGU Fall Meeting Abstracts, vol. 1 (2013), p. 1925

J.A. Rodriguez-Manfredi, M. de la Torre, P. Conrad, M. Lemmon, G.M. Martinez, C. Newman, M. Smith, T. Schofield, J. Gomez-Elvira, F. Gomez-Gomez, A.M. Harri, MEDA: an environmental and meteorological package for Mars 2020, in Lunar and Planetary Science Conference, vol. 45 (2014), p. 2837

J.A. Ryan, R.M. Henry, Mars atmospheric phenomena during major dust storms, as measured at surface. J. Geophys. Res., Solid Earth 84(B6), 2821-2829 (1979)

J.A. Ryan, R.D. Sharman, R.D. Lucich, Mars water vapor, near-surface. J. Geophys. Res., Oceans 87(C9), 7279-7284 (1982)

H. Savijärvi, A toy climate model for Mars. Icarus 242, 105-111 (2014)

H.I. Savijärvi, A.M. Harri, O. Kemppinen, Mars Science Laboratory diurnal moisture observations and column simulations. J. Geophys. Res., Planets 120, 1011-1021 (2015). doi:10.1002/2014JE004732

H. Savijärvi, A.M. Harri, O. Kemppinen, The diurnal water cycle at Curiosity: role of exchange with the regolith. Icarus 265, 63-69 (2016)

J. Schofield et al. The Mars Pathfinder Atmospheric Structure Investigation/Meteorology (ASI/MET) experiment. Science 278, 1752-1758 (1997)

N. Schorghofer, O. Aharonson, Stability and exchange of subsurface ice on Mars. J. Geophys. Res., Planets 1991-2012 110(E5), E05003 (2005)

A. Seiff, J.E. Tillman, J.R. Murphy, J.T. Schofield, D. Crisp, J.R. Barnes, C. LaBaw, C. Mahoney, J.D. Mihalov, G.R. Wilson, R. Haberle, The atmosphere structure and meteorology instrument on the Mars Pathfinder lander. J. Geophys. Res., Planets 102(E2), 4045-4056 (1997)

M.D. Smith, Interannual variability in TES atmospheric observations of Mars during 1999-2003. Icarus 167(1), 148-165 (2004)

M.D. Smith, Spacecraft observations of the Martian atmosphere. Annu. Rev. Earth Planet. Sci. 36, 191-219 (2008). doi:10.1146/annurev.earth.36.031207.124334

P.H. Smith, M.T. Lemmon, Opacity of the Martian atmosphere measured by the imager for Mars Pathfinder. J. Geophys. Res. 104, 8975-8985 (1999). doi:10.1029/1998JE900017

P.H. Smith, J.F. Bell, N.T. Bridges, D.T. Britt, L. Gaddis, R. Greeley, H.U. Keller, K.E. Herkenhoff, R. Jaumann, J.R. Johnson, R.L. Kirk, Results from the Mars Pathfinder camera. Science 278(5344), 17581765 (1997)

D.E. Smith, M.T. Zuber, S.C. Solomon, R.J. Phillips, J.W. Head, J.B. Garvin, W.B. Banerdt, D.O. Muhleman, G.H. Pettengill, G.A. Neumann, F.G. Lemoine, The global topography of Mars and implications for surface evolution. Science 284(5419), 1495-1503 (1999)

M.D. Smith, M.J. Wolff, M.T. Lemmon, N. Spanovich, D. Banfield, C.J. Budney, R.T. Clancy, A. Ghosh, G.A. Landis, P. Smith, B. Whitney, First atmospheric science results from the Mars Exploration Rovers Mini-TES. Science 306(5702), 1750-1753 (2004)

M.D. Smith, M.J. Wolff, N. Spanovich, A. Ghosh, D. Banfield, P.R. Christensen, G.A. Landis, S.W. Squyres, One Martian year of atmospheric observations using MER Mini-TES. J. Geophys. Res. 111, E12S13 (2006). doi:10.1029/2006JE002770

P.H. Smith, L.K. Tamppari, R.E. Arvidson, D. Bass, D. Blaney, W.V. Boynton, A. Carswell, D.C. Catling, B.C. Clark, T. Duck, E. DeJong, $\mathrm{H}_{2} \mathrm{O}$ at the Phoenix landing site. Science 325(5936), 58-61 (2009)

M.D. Smith, M.P. Zorzano, M. Lemmon, J. Martín-Torres, T.M. de Cal, Aerosol optical depth as observed by the Mars Science Laboratory REMS UV photodiodes. Icarus 280, 234-248 (2016)

N. Spanovich, M.D. Smith, P.H. Smith, M.J. Wolff, P.R. Christensen, S.W. Squyres, Surface and near-surface atmospheric temperatures for the Mars Exploration Rover landing sites. Icarus 180(2), 314-320 (2006)

A.L. Sprague, D.M. Hunten, R.E. Hill, B. Rizk, W.K. Wells, Martian water vapor, 1988-1995. J. Geophys. Res. 101(E10), 23,229-23,241 (1996)

S.W. Squyres, R.E. Arvidson, E.T. Baumgartner, J.F. Bell, P.R. Christensen, S. Gorevan, K.E. Herkenhoff, G. Klingelhöfer, M.B. Madsen, R.V. Morris, R. Rieder, Athena Mars rover science investigation. J. Geophys. Res., Planets 108(E12), 5141 (2003)

K. Steakley, J. Murphy, A year of convective vortex activity at Gale crater. Icarus 278, 180-193 (2016)

L.J. Steele, M.R. Balme, S.R. Lewis, A. Spiga, The water cycle and regolith-atmosphere interaction at Gale crater, Mars. Icarus 289, 56-79 (2017). doi:10.1016/j.icarus.2017.02.010

R. Sullivan, M. Golombek, G. Wilson, R. Greeley, M. Kraft, K. Herkenhoff, J. Murphy, P. Smith, Results of the Imager for Mars Pathfinder windsock experiment. J. Geophys. Res. 105, 24547-24562 (2000). doi:10.1029/1999JE001234 
J.L. Sutton, C.B. Leovy, J.E. Tillman, Diurnal variations of the Martian surface layer meteorological parameters during the first 45 sols at two Viking lander sites. J. Atmos. Sci. 35(12), 2346-2355 (1978)

L.K. Tamppari, D. Bass, B. Cantor, I. Daubar, C. Dickinson et al., Phoenix and MRO coordinated atmospheric measurements. J. Geophys. Res. 115, E00E17 (2010). doi:10.1029/2009JE003415

P.A. Taylor, D.C. Catling, M. Daly, C.S. Dickinson, H.P. Gunnlaugsson, A.-M. Harri, C.F. Lange, Temperature, pressure, and wind instrumentation in the Phoenix meteorological package. J. Geophys. Res. 113, E00A10 (2008). doi:10.1029/2007JE003015

P.A. Taylor, H. Kahanpää, W. Weng, A. Akingunola, C. Cook, M. Daly, C. Dickinson, A.M. Harri, D. Hill, V. Hipkin, J. Polkko, On pressure measurement and seasonal pressure variations during the Phoenix mission. J. Geophys. Res., Planets 115(E3) (2010)

J.E. Tillman, N.C. Johnson, P. Guttorp, D.B. Percival, The martian annual atmospheric pressure cycle: years without great dust storms. J. Geophys. Res., Planets 98(E6), 10963-10971 (1993)

J.E. Tillman, L. Landberg, S.E. Larsen, The boundary layer of Mars: fluxes, stability, turbulent spectra, and growth of the mixed layer. J. Atmos. Sci. 51(12), 1709-1727 (1994)

D.V. Titov, J. Rosenqvist, V.I. Moroz, A.V. Grigoriev, G. Arnold, Evidences of the regolith-atmosphere water exchange on Mars from the ISM (Phobos-2) infrared spectrometer observations. Adv. Space Res. 16(6), 23-33 (1995)

A.D. Toigo, M.I. Richardson, Seasonal variation of aerosols in the Martian atmosphere. J. Geophys. Res. 105(E2), 4109-4121 (2000). doi:10.1029/1999JE001132

D. Tyler Jr., J.R. Barnes, Mesoscale modeling of the circulation in the Gale Crater region: an investigation into the complex forcing of convective boundary layer depths. Mars Int. J. Mars Sci. Explor. 8, 58-77 (2013)

D. Tyler Jr., J.R. Barnes, Convergent crater circulations on Mars: influence on the surface pressure cycle and the depth of the convective boundary layer. Geophys. Res. Lett. 42(18), 7343-7350 (2015)

A.R. Vasavada, S. Piqueux, K.W. Lewis, M.T. Lemmon, M.D. Smith, Thermophysical properties along Curiosity's traverse in Gale crater, Mars. Icarus 284, 372-386 (2017)

T. Velasco, J.A. Rodríguez-Manfredi, The TWINS instrument on Board Mars Insight Mission, in General Assembly Conference, vol. 17 (2015), p. 2571

Á. Vicente-Retortillo, F. Valero, L. Vázquez, G.M. Martínez, A model to calculate solar radiation fluxes on the Martian surface. J. Space Weather Space Clim. 5(A33) (2015). doi:10.1051/swsc/2015035

S.D. Wall, Analysis of condensates formed at the Viking 2 Lander site: the first winter. Icarus 47(2), 173-183 (1981)

H. Wang, M.I. Richardson, R.J. Wilson, A.P. Ingersoll, A.D. Toigo, R.W. Zurek, Cyclones, tides, and the origin of a cross-equatorial dust storm on Mars. Geophys. Res. Lett. 30(9), 1488 (2003)

J.A. Whiteway, M. Daly, A. Carswell, T. Duck, C. Dickinson, L. Komguem, C. Cook, Lidar on the Phoenix mission to Mars. J. Geophys. Res. 113, E00A08 (2008). doi:10.1029/2007JE003002

J.A. Whiteway, L. Komguem, C. Dickinson, C. Cook, M. Illnicki, J. Seabrook, V. Popovici, T.J. Duck, R. Davy, P.A. Taylor, J. Pathak, Mars water-ice clouds and precipitation. Science 325(5936), $68-70$ (2009)

R.J. Wilson, A general circulation model simulation of the Martian polar warming. Geophys. Res. Lett. 24(2), $123-126$ (1997)

R.J. Wilson, K. Hamilton, Comprehensive model simulation of thermal tides in the Martian atmosphere. J. Atmos. Sci. 53(9), 1290-1326 (1996)

D. Zandonadi, N.O. Renno, E. Fischer, WET-a soil wetness sensor for Mars, in 66th International Astronautical Congress, Jerusalem, Israel (2015)

A.P. Zent, R.M. Haberle, H.C. Houben, B.M. Jakosky, A coupled subsurface-boundary layer model of water on Mars. J. Geophys. Res., Planets 98(E2), 3319-3337 (1993)

A.P. Zent, J. Howard, R.C. Quinn, $\mathrm{H}_{2} \mathrm{O}$ adsorption on smectites: application to the diurnal variation of $\mathrm{H}_{2} \mathrm{O}$ in the martian atmosphere. J. Geophys. Res. 106, 14667-14674 (2001)

A.P. Zent, M.H. Hecht, D.R. Cobos, G.S. Campbell, C.S. Campbell, G. Cardell, M.C. Foote, S.E. Wood, M. Mehta, Thermal and Electrical Conductivity Probe (TECP) for Phoenix. J. Geophys. Res. 114, E00A27 (2009). doi:10.1029/2007JE003052

A.P. Zent, M.H. Hecht, D.R. Cobos, S.E. Wood, T.L. Hudson, S.M. Milkovich, L.P. DeFlores, M.T. Mellon, Initial results from the thermal and electrical conductivity probe (TECP) on Phoenix. J. Geophys. Res., Planets 115(E3), E00E14 (2010)

A.P. Zent, M.H. Hecht, T.L. Hudson, S.E. Wood, V.F. Chevrier, A revised calibration function and results for the Phoenix mission TECP relative humidity sensor. J. Geophys. Res., Planets 121, 626-651 (2016). doi:10.1002/2015JE004933

R.W. Zurek, Diurnal tide in the Martian atmosphere. J. Atmos. Sci. 33(2), 321-337 (1976)

R.W. Zurek, Free and forced modes in the Martian atmosphere. J. Geophys. Res., Atmos. 93(D8), 9452-9462 (1988)

R.W. Zurek, C.B. Leovy, Thermal tides in the dusty Martian atmosphere: a verification of theory. Science 213(4506), 437-439 (1981) 